\title{
Die Fälschungen des Reichskanzlers Kaspar Schlick ${ }^{1}$ ). \\ Von
}

\author{
Max Dvoŕák.
}

Es ist nicht das erstemal, dass Schlick'sche Urkunden angezweifelt werden. Graf Sternberg wies in dem angeblich von Sigmund den Schlick verliehenen Münz- und Berg-Privileg²) eine plumpe Fälschung des 16. Jahrhunderts nach ${ }^{3}$ ). Ihm schloss sich Palacký an. Die Erben des Kaspar Schlick, dentn seine böhmischen Besitzthümer erhalten blieben, waren ein gewaltthätiges Geschlecht; bald zersch̆lugen sie sich mit ibren Vasallen, mit ihren Nachbaren, mit dem ganzen Lande; Mord und Verrath, Gewalt und List benützten sie um ihre Ziele zu erreichen, als ob italienische Condottieri nach dem Norden versehlagen worden wären. $\mathrm{Zu}$ wiederholtenmale vor die Landrechte gerufen, legten sie im J. 1486 eine Urkunde vor, in der von Sigismund dem Kaspar Schlick und seinen Erben eine volle Gerichtsexemption verliehen wird. Palacký nahm an, die Urkunde wäre eine von den Erben Kaspars ad hoc fabricirte Fälschung gewesen, zu der sich wohl noch andere ge-

1) Der Aufsatz wurde schon vor mehr als Jahresfrist der Redaction übergeben, konnte aber theils wegen des leidigen Raummangels, theils wegen der Beschaffing der Facsimiles nicht früher veröffentlicht werden. Unterdes hat, wie Herr Professor Aloys Schulte in Breslau mir mittheilt, einer seiner Schüler, Herr Dr. Alfred Pennrich, ganz selbständig denselben Stoff bearbeitet, ohne freilich in das handschriftliche Material Einsicht nehmen zu können; diese Arbeit soll nach dem getroffenen Uebereinkommen gleichzeitig publicirt werden.

2) Altmann Reg. Sigmunds 12063.

E. Mühlbacher.

s) Geschichte der böhmischen Bergwerke I. $313 \mathrm{ff}$. 
sellten. „Indessen fanden die Herren Schlick eine neue Art, sich einem Rechtsstreit zu entziehen: sie liessen sich mit nachgemachten Urkunden versehen, mittelst welcher Kaiser Sigismund ihrem Geschlechte ansehnliche bis dahin unerhörte Immunitäten, Rechte und Begünstigungen ertheilt haben sollte ${ }^{1}$ ). Palacký war es offenbar nicht bekannt, dass uns die im J. 1486 vorgelegte Urkunde erhalten ist und weder Unmögliches noch Unerhörtes enthält; er stützt seine Annahme auf den Beschluss der Beisitzer der Landrechte. Dieselben erklärten die Urkunde für rechtsungiltig mit der Begründung, dass Sigismund nicht das Recht hatte die Begünstigungen des Diploms gegen die Satzungen und Freiheiten des Königreichs Böhmen zu ertheilen²) und Palacký interpretirt diese Entscheidung in der Weise, dass die Richter die Echtheit der vorgelegten Urkunde nicht $\mathrm{zu}$ bestreiten wussten und sie einfach annullirten.

Altmann setzt in seinem Regestenwerke Fragezeichen zu einigen von Sigismund für die Schlick ausgestellten Urkunden, ohne jedoch die Gründe seiner Bezweiflung ${ }^{3}$ ) oder die muthmassliche Entstehungszeit anzuf ühren. Eine der Wahrheit sehr nahe kommende Vermuthung hat H. Gradl, der sich mit der ältesten Geschichte der Schlick beschäftigte und dem einzelne mit den thatsächlichen Verhältnissen nicht übereinstimmende Angaben der Urkunden über die Genealogie des Geschlechtes aufgefallen waren, ausgesprochen: er möchte darin das einfache Dictat des strebsamen Kanzlers an die untergeordneten Schreiber sehen, Angaben, die Kaiser Sigismund leicht hinnahm ${ }^{4}$ ).

Ich glaube den Beweis führen zu können, dass Kaspar Schlick sein Amt missbrauchte, um mit allen Mitteln, die ihn in der Kanzlei zur Verfügung standen, eine Reihe von Orkunden für sich und seine Familie zu fälschen. Damit wird die Frage über die Grenzen der monografischen und localen Forschung gerückt. Nicht nur weil es sich um Kanzleifälschungen handelt und um Fälschungen, die ein methodisches Interesse bieten. Ist ja Kaspar Schlick eine nicht minder bedeutende Persönlichkeit als Enea Silvio, eine Erscheinung, bei der sowohl ein starkes individuelles Gepräge, als die Signatur des Zeitalters gleich scharf zu Tage treten.

\footnotetext{
1) Geschichte von Böhmen XI. 281.

${ }^{2}$ ) Der Beschluss wurde in die Landesordnung vom J. 1500 \& 10 aufgenommen.

s) Mit Ausnahme von $\mathrm{Nr}$. 4889, wo er auf die Nichtübereinstimmung des Titels des unterfertigenden Protonotars mit dem Datum verweist.

4) Zur ältesten Geschichte der Schlick. Organ der. heraldischen Gesellschaft Adler 1886
} 
Eine Lebensskizze des Kanzlers brauche ich nicht zu geben, das wichtigste findet man in eivem Aufsatze von Krones in der Allgem. Deutschen Biographie ${ }^{1}$ ). Als Schreiber trat Kaspar in die Kanzlei ein, wurde Protonotar, dann im J. 1433 Kanzler, bewährte sich in politischen Geschäften und hat als Kanzler dreier Herrscher auf die Richtung der königlichen Politik zwei Jahrzehnte hindurch einen grossen Einfluss ausgeübt, eine Zeit lang sie selbständig geführt. Er war der erste Laienkanzler, die Verweltlichung der Kanzlei vermochte sich bereits bis auf die leitenden Stellen zu erstrecken. Nicht minder wichtig ist eine andere Wandlung, die sich ebenfalls seit den Zeiten Friedrichs in das alte Reichsleben eingeschlichen hat, aus der jedoch im Norden erst Sigismund vollends die Consequenzen zu ziehen sich gezwungen sah und welcher Schlick sein Aufkommen verdankt. Der Kanzler war ein Staatsmann in macchiavellischer Bedeutung des Wortes, dessen Dienste von drei Regenten in Anspruch genommen wurden. Die alte Welt war zertrümmert, der Kaiser, der Papst, der alte Adel standen verständnis- und hilflos den neuen Bestrebungen gegenüber, es ist nur natürlich, dass statt einer Ideen-, Reichs- oder Kircheupolitik eine vor allem auf Wahrung der persönlichen Familien- und dynastischen Interessen hinausgehende Tendenz platzgreift. Der Adel nach und nach zu einem Geburtsadel sich ausbildend, schliesst sich ab, der Papst ist ein italienischer Landesfürst und der Kaiser, der seine Hausmacht verloren hat, wird zu einem Abenteurer wie Sigismund. Die alte Reichsverfassung war längst durch das neue geistige Leben uud durch territoriale Entwickelung ausser Curs gesetzt und eine leere Form geworden. Wie nie früher musste das Kaiserthum erst gewonnen werden, einen Inhalt bekommen. Die Politik wurde zum grossen Theile Privatsache des Herrschers, der Dynastie, es ist dies die Grundquelle des Absolutismus. An die Stelle der Würde, des Standes, der Corporation tritt die objective persönliche Leistung, erst später das Amt. An die Stelle des Er:bischofs Ernst von Pardubitz tritt ein Parvenu im Sinne der Zeit, ein Kaspar Schlick. Man begreift, warum sich die Zeitgenussen wundern: „Hat jenıand gehört, dass eines Bürgers Sohn zu Deutschland so mächtig geworden!“2). Aus den Correspondenzen zwischen Schlick und Olrich von Rusenberg kann man entnehmen, mit welcher Verachtung der letztere auf den Kanzler, deu Berather des Kaisers in allen wichtigen Dingen herabsah, etwa so wie auf die zu Macht und Einfluss in Böhmen gekommenen Hussitenführer. Und Schlick fälschte

1) Bd. 31. Der Aufsatz beschäftigt sich nicht mit Kritik der einzelnen Nachrichten.

2) Windecke 381 . 
eine Reihe von Standeserhebungen; mit Recht wurde unlängst darauf hingewiesen, dass Fälschungen gar oft ein schärferes Licht auf ihre Entstehungszeit und Urheber werfen, als echte Documente ${ }^{1}$ ).

Als Ausgangspunkt unserer Beweisführung nehmen wir eine Urkunde Sigismunds ddo. 1422, Juli 16. Nürnberg, durch welche Kaspar Schlick in den Freiherrnstand erhoben wird ${ }^{2}$ ). Die Urkunde ist uns in Original erhalten ${ }^{3}$ ) und ausserdem in einer Bestätigungsurkunde Friedrichs vom J. 1442 im Reichsregister 0.164. Das Orignal ist von einer auch sonst in echten Urkunden nachweisbaren Kauzleischrift geschrieben und mit einem echten an schwarzgelben Schnüreu hängenden Majestätssiegel (Heffner, Taf. XIV. 98) versehen. Die Urkunde ist also, was äussere Merkmale anbelangt, vollständig kanzleigenı̈ss. Wie steht es mit dem Iuhalt? Da finden wir sonderbare Dinge. Es wird über die Herkunft des Schlick berichtet. Es wird erzählt, dass Sigismund von vielen hochgeborenen und erlauchten Männern, Grafen und Freiherrn und vor allem von dem Grafen Wilhelm von Prate benachrichtigt und hinlänglich unterrichtet wurde, dass Kaspar Schlick von mütterlicher Seite her aus dem berühmten Hause der Grafen von Collalto und Sant Salvator, welche in vergaugenen Zeiten die Mark Treviso und andere grosse Herrschaften besessen haben und noch heute mehrere besitzen, in gerader Abstammung ent.prossen ist, da seine Mutter Constanze die legitime und einzige Erbin und Tochter des Grafen Roland von Collalto und seiner Gemihlin aus der Familie der Grafen von Camin gewesen ist. Von der väterlichen Seite her stamme Kaspar von dem ,edlen und namhaftigen" Heinrich Schlick, der einem ritturlichen Geschlechte angehörte und von Sigismund zu einem höheren Adel erhoben warde. Obwohl also über die vornehme Herkunft des Schlick kein Zweifel bestehen kann, wird er dennoch auf sein Ersuchen „ad capienda et tenenda bona sibi de iure ex successione materna conpetentia et debenda", in den Freiherrnstand erhoben (in liberum procerem et baronem sacri imperii). Dann werden die Verdienste Schlicks geschildert, die er sich um den König in Spanien, Frankreich, Eugland, im Kampfe gegen die Hussiten und Türken und durch zahlreiche Missionen bei verschiedenen Königen erworben hat. Seine von der Mutter ererbten Anrechte sollen dadurch uicht beeinträchtigt werden, dass der letzteren von den Grafen von Coilalto alle ihre Privilegien, Handvesten uud Nachweise durch Kerker und Gefangenschaft abgepresst

1) Dopsch in der Beilage zur Münchner allgemeinen Zeitung 1898, Nr. 181.

2) Altmann Reg. 4889 (wahrscheinlich Fälschung).

3) Im Schlickschen Archiv in Kopidlno IV. 2. Beilage 1. 
wurden ${ }^{1}$ ), wovon Sigismund ebenfalls von den genannten Grafen und Herren eine Nachricht bekommen hat. Von nun an soll ihm gegen die Grafen von Collalto Hilfe geleistet werden. Es wird ihm feruer bewilligt sein Wappen durch das seiner Mutter zu bessern. Als Zeugen werden genannt Herzog Albrecht von Sachsen, Bischof Georg von Passau und Wilhelm von Prate.

Es ist nicht schwer den Beweis zu führen, dass eine Reihe von Angaben der Urkunde nicht auf Wahrheit beruhen. Vor allem die Erzählung über die adelige Abstammung des Kaspar Schlick. Wir sind über seine Herkunft ziemlich genau unterrichtet. Windecke sagt darüber: „der keiser hette einen, der hiesz Kasper Slick und was eines burgers son von Eger und was zu dem keisar komen, do man schreip 1416 jor" 2). Diese Nachricht findet eine volle Bestätigung in den Stadtbüchern von Eger, uus denen die auf die Schlick sich bezieheuden Notizen von Gradl veröffentlicht wurd $-\mathbf{n}^{3}$ ). Der Vater Kaspars, Heinrich ist seit 1394 in Eiger ansässig, wohin die Mutter des letzteren und seine Brüder schon früher übersiedelt zu sein scheinen. Nach den Abgaben zu schliessen, war die Familie recht unbemittelt. Heinrich Schlick wohnte in der Judengasse und betrieb Tuchhaudel ${ }^{4}$ ), wobei er sich rasch ein Vermögen erworben hat. In den J. 1407-8 wurde er in den Stadtrath gewählt, welchem er bis zum J. 1426 angehört. Zum letztenmal wird er im J. 1431 genannt ${ }^{5}$ ). In den J. 1395-1426 war er nie längere Zeit von Eger abwesend. (Man vermerkte dies stets in den Stadtbüchern). Als Abgesandter des Egrer Rathes kam er einigemal nach Nürnberg' ${ }^{6}$ ).

Eine relativ sichere Quelle für die Feststellung eines fraglichen Standesranges im späteren Mittelalter besitzen wir in dem Titelwesen. Etwa seit dem Ende des 12. Jhd. wurden einzelne Prädikate in bestimmte Beziehung zu verschiedenen socialen Klassen gesetzt uud ,seit der Mitte des 13. Jhd. hatte sich dieser Gebrauch so fest gestaltet, dass darnach häufig die Zeugen in den Kaiserurkunden klassificirt

1) avunculi tui comites de Colalto moderni dicte matri tue Constancie vinculis et captivitati mancipate universas litteras, munimenta et probaciones nullo iure previo prout a predictis comitibus et baronibus clarissina informatione percepimus, durius abegerunt.

2) S. 380 .

3) Zur ältesten Geschichte der Schlick a. o. a. St.

4) Gradl a. a. St. vgl. Janssen, Reichscorrespondenz I. 359 und I. 609.

5) Reichsregister J. 99.

R) Altmann 7183. RA. 8. 44 und 49 . 
wurden“ 1). Die Angehörigen des Ritterstandes werden als namhaftig, fest, als famosi, strenui, die Adeligen im allgemeinen als edle, nobiles bezeichnet. Bei Heinrich Schlick finden wir weder die eine noch die andere Bezeichnung. In den Stadtbüchern von Eger heisst er einfach wie die sonstigen Bürger Schlick ohue jedes Prädikat - ein höherer Stand wird daselbst stets mit dem ihn gebührenden Titel bezeichnet, oder man unterlässt wenigstens nicht dem Namen ein „Herr" vorzusetzen, so werden auch später diejenigen Schlick, welche in den Ritter- und Adelsstand erhoben wurden als Herren, als nambaftig und edel genannt ${ }^{2}$ ). In den kaiserlichen Urkunden führt Schlick ebenfalls deu bürgerlichen Titel erbar, ersam, honestus ${ }^{3}$ ). Es ist also zweifellos, dass Heinrich Schlick weder einem Adels- noch Rittergeschlechte angehörte $\left.{ }^{4}\right)$.

Ebensowenig war die Mutter Kaspars eine Gräfin Collalto. Die Genealogie der Grafen weiss nichts von einer Tochter Rolands und von jener romanhaften Geschichte, derzufolge sie von ihren Verwandten eingekerkert und aller ihrer Privilegien beraubt worden wäre. Dagegen wissen wir, dass die Mutter Kaspars eine Egrerin war, ihr Vater lebte in Eger $^{5}$ ). Sie processirt um Pfennige, in den Stadtbüchern wird sie nie Frau genannt, sondern einfach die Schlickin oder Heinrich Schlickin ${ }^{6}$ ). In unserer Urkunde wird von ihr wie von einer Todten gesprochen, sie und ihr Vater leben jedoch noch im J. 14257).

Kann man annehmen, dass die Erdichtungen der Urkunde etwa "von Sigismund leicht hingenommen wurden?" Er mochte vielleicht betreffs der Abstammung der Mutter des Schlick dem letzteren guten Glauben geschenkt haben, doch Heinrich Schlick war eine bei Hofe nicht unbekannte Persönlichkeit. Im J. 1420 wird ein Heinrich Schlick unter die Familiares, aufgenommen ${ }^{8}$ ). Es kann sich hier nur um den Vater Kaspars handeln, der auch noch im J. 1428 und im J. 1429 thatsächlich unter den Familiares genannt wird ${ }^{9}$ ). Wir wissen ferner,

1) Ficker, Reichsfürstenstand I. 147. Vgl. die Titulaturenübersicht im Collectarius des Johann von Gelnhausen publ. von Kaiser S. 134 ff. (Strassburg 1898) Auch in dem interessanten Kanzleibuche aus der Kanzlei Sigismunds im Wiener Staatsarchiv (als Reichsregister D) findet man eine Sammlung von Titulaturen.

2) Gradl, Reg. 188, 196, 209, 211, 218 usw.

3) Reicheregister J. 2, 17, 99v. So auch in der Urkunde Johanns Landgrafen von Leuchtenberg Gradl, Reg. 47.

4) Vermuthungen über die ältere Geschichte der Familie bej Gradl, Mitth.

d. Ver. für Gesch. d. Deutsç. in Böhmen XX. 347.

5) Gradl, Reg. 93, 87 uud S. 23.

6) Dasebst, Reg. 31, 35, 93, 97 und S. 23.

7) Daselbst Reg. 97.

8) Altmann 3997.

8) Reichsregister J. 2 und 17. 
dass er von seiner Vaterstadt zu Sigismund geschickt wurde1). Sigismund hätte also Angaben bestätigt, deren Unrichtigkeit allgemein bekannt seiu musste.

Der Inhalt und der ganze Charakter der Urkunde sticht sehr ab von Verleihungen an andere Kanzleibeamte ${ }^{2}$ ). Von einem ähulichen Pathos ist da keine Rede, ebensowenig wie in den Diplomen, welche Schlick in den nächstfolgenden Jahren erhalten hat ${ }^{3}$ ). Die Urkunde vom J. 1422 lässt Schlick bereits als eine besonders wichtige, einflussreiche Persönlichkeit an Hofe erscheinen. Das wird widerlegt durch das, was uns über ihn und seine Stellung in dieser Zeit sonst bekannt ist.

Schlick trat wahrscheinlich im J. 1415 in die Kanzlei ein ${ }^{4}$ ). Im J. 1418 wurde er mit einer Reihe von anderen unter die Familiares aufgenommen. In der darauf sich beziehenden Eintragung im Register führt er keinen Amtstitel, obwohl derselbe sonst genannt wird5). Aus den J. 1418-1424 besitzen wir keine Notiz über Schlick. In den J. 1424-27 (April 9.) ist er Notar und Sekretär6). Erst aus dem Juli 1427 stammen seine ersten Unterfertigungen, erst in dieser Zeit ist er Protonotar geworden ${ }^{7}$ ).

In der Urkunde wird berichtet, dass Schlick (bereits vor dem J. 1422) in verschiedenen Gesandtschaften zu eiızelnen Königen und Fürsten verwendet wurde. Erst im J. 1427 wird eine Sendung Schlicks erwähnt, er wurde geschickt, um Wend von Ilenburg und vier anderen Kommissären königliche Instructionen betreffs der Grenzstreitigkeiten zwischen dem Polenkönig und dem deutschen Orden zo überbringen und von dem Hochmeister des deutschen Ordens Sehiffmacher zu holen ${ }^{8}$ ). Und in einer späteren Fälschung, in der die Verdienste

3) Reichsregister J. 17, vgl. auch Reichstagsacten 8. 44 und 49.

9) Vgl. z. B. die Adelserhöhung des Kalde vom 5. Dec. 14:0 im Reichsregister G. 107, des Wacker vom 3. Jan. 1430 im RR. J. 601, des Ebbracht vom T. April 1439 im RR. K. 202 u. a. Man benützte für die Nobilitirungen ein ziemlich constantes Formular, für welches man Vorlagen in dem Kanzleibuche (Reichsregister D) bessass.

3) Aus früherer Zeit besitzen wir bezeichnender Weise nux eine und zwar verdächtige Urkunde Sigismunds für Heinrich und Kaspar Schlick (1416, Aug. 13. Canterbury), in welcher denselben ihr altes Wappen vermehrt und bestätigt wird. Altmann 1974.

4) F ür dieses Jabr spricht die Nachricht über seinen Aufenthalt in Aragonien. Vgl. Beilage VII.

5) Data est littera familiaritatis Caspari Slick de Egra RR. F. 103.

6) Altmann 5796, 5877, 6833, 6887.

i) Altmann 6928.

8) Altmann 6833 und 6883 . 
Schlicks ausführlich aufgezïhlt werden, wird die Reise nach Polen und Lithauen als die erste seiner Missionen genannt1).

Er.cheint also die Kenntnisname Sigismunds von dem voriiegenden Wortlaute der Urkunde alદ höchst uuwahrscheinlich, so wäre es vielleicht immerhin möglich, dass von dem König die einfache Verfügung getroffen wurde und dass die Textherstellung und Verunechtung desselben dnrch unrichtige Angaben auf den in der Kanzlei beschäftigten Empfänger zurückzutühren ist. Die Untersuchungen Lindners und Seeligers über die einzeluen Stadien der Urkundenausstellung unter den Luxenburgern und die Betheiligung des Herrschers an denselben sind noch lange nicht abschliessend und dürften manche Ergänzung erfahren, aber so viel steht jedenfalls a priori und auf Grund des bekannt gewordenen Matirials ausser Frage, dass die endyiltige Niederschrift der Urkunde nur in besonderen Fällen der persönlichen Controle des Königs unterworfen war.

Aber die Sache ist an und für sich unwahrscheinlich. Schlick war in dieser Zeit ein untergeordneter Beamter, von der Einschmuggelung und Uustilisirung hätte wenigstens der Siegelbewahrer also der Kanzler wissen müssen ${ }^{2}$, man nüsste ein Kanzleicomplot annehmen. Gegenstandslos wird der Eiuwand durch den Nachweis, dass die Urkunde nicht im J. 1422 wie sie vorgibt, sondern später entstanden ist und dass die Standeserhebung Schlicks, die ihr zu Grunde liegt, ebenfalls im J. $1422 \mathrm{nicht}$ erfolgte. Wenn man auch kein gresses Gewicht darauf legen lann, dass die Ortsangabe nicht zum Itinerar passt, ist es doch anzuführen ${ }^{3}$ ). In der Urkunde wird erzählt, dass Sigisinund von vielen Grafen und Magnaten über die Abstammung des Schlick von deu Grafen von Collalto unterrichtet wurde. Im J. 1422 und in Nürnberg? In einer späteren Fälschung Schlicks wird dieselbe Behauptung wiederholt, mit dem Unterschiede, dass es nun in Italien, als der Kaiser daselbst weilte, also nach dem Jahre 1431 geschehen sein soll ${ }^{4}$ ). Und in spätere Jahre verweist selbst die Erfindung der Fabel. Bis zum J. 142. war Schlick nicht in Italien. Man kann in älteren Biographien Schlicks lesen, dass er wahrscheinlich an einer italienischen Universität seine Ausbildung gefunden hat. Das ist aus der Luft gegriffen und wird durch Schlick selbst widerlegt ${ }^{5}$ ). Und seit

1) Beilage VII.

2) Vgl. Lindner, Das Urkundenwesen Karls IV. usw. 146.

3) Die Urkunde ist von 16. Juli und von Nürnberg datirt, wohin Sigismund erst am 24. gekommen ist.

4) Beilage VII.

5) In der Rede, welche er im J. 1444 in Wiener-Neustadt hielt, um den 
seiner Aufnalıme in die Kanzlei war Schlick ebenfalls nicht in Italien, wenn nicht auch aus anderen Gründen, so sicher aus dem, dass er es gewiss in die Drkunde oder in eine der späteren aufgenommen hätte, wie er dies bezüglich seines Aufenthaltes in Frankreich, Spanien, England gethan. Aber das Märchen setzt doch einige Vertrautheit mit italienischen Verhältnissen voraus.

Der Erbtheil seiner Mutter, die Güter der Collalto, welche ihr mit Gewalt von den Verwandten entrissen wurden, werden ihm verliehen und befohlen, naan möge ihn in der Erwerbung derselben unterstützen. Das ist eine Stelle, die wir kaum nur anf eine freie Stilisirung Schlicks zurückführen können. Aber abgesehen davon, eine solche Forderung war sinnlos im J. 1422, wohl aber verständlich in späteren Jahren.

Eine Reihe von echten Urkunden macht es zweiffllos, dass Schlick auch vom J. 1422 an, nicht dem Adelsstande angehörte. In keiner dieser Urkunden kommt der ihn durch die angebliche Standeserhebung vom J. 1422 gebühreude Titel edel, nobilis vor ${ }^{1}$ ). Erst in J. 1419 wurde Schlick in Ungarn nach eigenen Zugeständnis unter rittermässige Leute von Sigismund erhoben²) und führt von da an das Prädikat derselben nambaftig, oder vest, wogegen seine Brüder und Verwandten wie früher als einfache Bürger ersam oder erbar heissen ${ }^{3}$ ). Eine so konsequente Verwechslung der Titulatur wäre bei einer Privatperson unwahrscheinlich, bei einem Kanzleibeamten, welcher die Herstellung der ihn betreffenden Urkunden überwachen konnte und auf die eigene Ehrung und Hervorhebung, wie wir wissen, stets bedacht war, ist sie ausgeschlossen. Wenn Barbaro, der höfliche Venetianer, in dieser Zeit an Schlick schreibt, nennt er ibn doctissimus vir, nichts mehr ${ }^{4}$ ). Weder Kaspar Schlick noch jemand seines Geschlechtes gebraucht die ihnen in der Urkuude vom Jahre 1422 verliehene Wappenvermehrung 5 ). Und zuletzt: wir wissen, wann Schlick von Sigismund thatsächlich in den Freiherrnstand erhoben wurde.

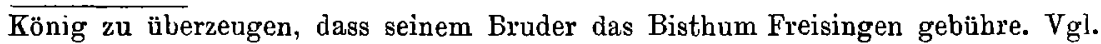
Voigt, Enea Silvio I. 275.

1) Reichsregister H. fol. 28|v, 43, RA. 9, 306, 339. RR. J. 66/v, 67 Gradl Reg. 136, RR. J. 99/v, 106/v, 148/v, 149/v, 150, 162/v, 172, 191, 194.

2) Rf deuntibus autem nobis ad Constanciam et completa sanctissima unione ecclesie properantibusque nobis ad peculiare regnum nostrum Hungarie, ubi insultantibus Turcis apparatum bellicum instruximus et repressis eis constructoque castro Gorini victores recessimus, te tunc milicie premio verbo regio dignum iudicantes. Beilage VII.

3) Reichsregister J. 2.

4) Codex der Wiener Hof bibl. 5667 fol. $2 \mathrm{ff}$.

5) Zu vglchen : das Wappen des Niklas Schlick an dem Siegel der Urkunde Gradl Reg. 104 vom J. 1426, Niklas Schlick des Aelt. an der Urkunde Gradl 
Seit dem J. 1427 wächst rasch der Einfluss Schlicks. Fast sämmtliche Urkunden aus den folgenden Jahren sind von ibm gefertigt. Der Kanzler Johann von Agram tritt immer mehr zuräck. In einem Briefe vom 5. Aug. 1429 nennt sich Schlick zum erstenmale: „beider kuniglicher Insigel iczund vicecancellarius" ${ }^{1}$ ). Es ist dies nicht so aufzufassen, als ob er der Nachfolger Johanns geworden wäre. Der letztere bleibt Kanzler und unterfertigt auch noch einigemal, zuletzt am 24. Aug. $1431^{2}$ ). Schlick hat dagegen die eigentliche Leitung der Kanzlei, er ist der Siegelbewahrer und wird abwechselud Vicekanzler und Protonotar, manchmal beides nebeneinander genannt. Nachdem Sigismund nach dem Süden aufgebrochen war, hört die Betheiligung des Bischofs an Kanzleigeschäften und Rathssachen ganz auf, er scheınt den König nicht begleitet zu haben ${ }^{3}$ ). Am 12. Mai 1432 fügt Schlick zum erstenmale in einer Kanzleiunterfertigung seinem Namen den Titel Vicekanzler bei, von da an wird er auch nicht mehr Protonotar genannt $\left.{ }^{4}\right)$.

In Italien, in jener Zeit als Sigismund von den Venetianern und Florentinern verlacht, von seinem Bundesgenossen Visconti wie ein Schulbube oder wie ein Landstreicher behandelt, von dem Papste mit dem Banne bedroht und ebenfalls verlacht, die härteste Schule seines Lebens durchmachen musste, ist dann Schlick der Vertraute und Rathgeber des Königs geworden. Er führte die Verhandlungen mit den Florentinern und Venetianern ${ }^{5}$ ) uud wurde von Sigismund zu dem Papste geschickt ${ }^{6}$ ). Vom Krönungstage datirt die erste Unterfertigung Schlicks als Kanzler?). An demselben Tage wurde er mit zwei Brüdern

Reg. 154 vom J. ]431, des Mathias Schlick vom J. 1436 an der Urkunde Gradl Reg. 207 abgebildetet im Oberbayrischen Archiv XXIX. Taf. 4, des Mathias und Wilhelm Schlick vom J. 1438 an der Urkunde Gradl Reg. 218 und die Siegel Kaspars an den Briefen an Ulrich von Rosenberg im Wittingauer Archive. Ueber die Siegel im Egrer Archive hat mir Herr Archivar Dr. Siegl freundlichst Auskunft ertheilt.

1) RA. 9. 306.

2) Altmann, 8802 .

3) Kanzler nennt er sich noch 1432 Aug. 25. Kaproncza. Palacký, Urk. Beiträge II. 307 .

4) 1429 Okt. 20: Dem erbern und weisen herrn Caspar Slicken prothonotario und secretario ectzund vicecancellario Reichsregister G. 339. Protonotar : 1430 Jan. 20 (Altmann 7602), Jan. 26 (7614 und 7617), Jan. 31 (7620) Febr. 6 (7629) Vicekanzler, Protonotar und Sekretär Oct. 16 (7875), Protonotar 1431 Febr. 2 (RR. J. 172) Vicekanzler und Protonotar Juli 20 (87:6), von da nur Vicekanzler.

5) Vgl. Altmann 9350, RA. XI. 5, 6, 24 und Beilage VIII.

6) Vgl. Aschbach IV, 95, Anm. 90 und Beilage VIIL.

7) Altmann 9436. Dass sich Schlick in der Unterfertigung auch noch später Vicekanzler nennt (2., 21., 22., 28. Juni, Altmann 9478, 9506, 9512 9513, 9528), 
und anderen aus der Gefolgschaft des Kaisers auf der Tiberbrücke zum Ritter geschlagen. Voll Freude berichtet ein Egrer in seine Heimat über diese grosse Auszeichnung, welche ihren Landsleuten zu theil wurde ${ }^{1}$ ) und titel vergisst der Kanzler von da an fast nie seiner Unterschrift das Wort miles beizufügen. Mit dem Ritterschlage auf der Tiberbrücke war in einzelnen Füllen eine Nobilitation verbunden ${ }^{2}$ ). Windecke berichtet, dass es auch bei Schlick der Fall war ${ }^{3}$ ). Es liegt kein Grund vor diese Nachricht anzuzweifeln; Windecke staud in engen Beziehungen zu Schlick, dem er ein Exemplar seiner Compilation gewidmet hat und die Vorgänge bei einer Kaiserkrönung waren, durch Zeitungen verbreitet, überall bekannt. Auch wird Kaspar Schlick und seinen zwei Brüdern, von denen wir wissen, dass sie mit ihm zugleich zu Rittern geschlagen wurden, von dem Krönungstage an der Titel edel, nobilis in Kaiserurkunden und allen übrigen durchwegs gegeben, ebenso consequent, wie es früher nicht geschah ${ }^{4}$ ). Die sonstigen Schlick führen wie früher das bürgerliche Prädikat ${ }^{5}$ ). Barbaro nennt Kaspar nuu mit Humanistenüberschwänglichkeit illustrissimns eques ${ }^{6}$ ). Es ist also zweifellos: erst im J. 1433 wurde Schlick von Sigismund in den Freiherrnstand erhoben und die Urkunde vom J. 1422 ist eine Fälschung.

Es gibt noch einen Beweis dafür, der allein genügen würde. Es wurde gesagt, dass die Urkunde, was äussere Merkmale anbelangt,

dürfte so zu erklären sein, dass man für diese Urkunden Membranen mit seiner alten Unterfertigung benützte. Lindner in Quiddes Zeitschrift IV, 347.

1) Gradl Reg. 178. Am 1. Juni verlieh Sigismund dem Kanzler das lateranische Pfalzgrafenamt. (Lünig RA. Sp. saec. II, 1175) Altmann zweifelt diese Urkunde an, wohl ohne Grund. Das Pfalzgrafenamt wurde in Rom an gar viele verliehen, an Leute von geringerer Bedeutung als der Kanzler.

Der Inhalt der Urkunde deckt sich mit jenem der sonstigen Urkunden dieser Art. Warum Altmann zu der Unterfertigung: Ad m. d. i, die auch sonst vorkommt ein sic macht, weiss ich nicht. Ueberdies nennt sich Schlick in der Unterfertigung einex drei Tage später datirten Urkunde (Altmann 9478) cancellarius et comes ac capitaneus terrarum Egrae, was ja doch nur auf die Erhebung zum Pfalzgrafen zu beziehen ist. Die fast gleichlautende Urkunde Sigismunds rom 8. August (gedruckt bei Lünig a. o. St. 1177), in welcher den $2 w e i$ Brüdern Kaspars Mathăus und Heinrich das Pfalzgrafenamt verliehen wird, zweifelt Altmann nicht an.

2) Vgl. die Urkunde für Brisacher über den Ritterschlag auf der Tiberbrücke vom 31. Mai 1433. Altmann 9434 .

3) 380. do macht der keiser Casper Slick zu eime römschen canzler und macht in zu einem friherrn und slug in selber ritter.

4) Vgl. die Urkunden Altmann 9588, 9670, 9833, Gradl Reg. 188, 9843, 9956, 10007, 10113,10403, 10414, 10441, 10848, 10875, 10957 usw.

5) Vgl. die Urkunden Altmann 10786, 10901, Gradl Reg. 207.

в) Cod. der Wiener Hof bibl. 5667 fol. 13. 
vollkommen unverdächtig sei. Und doch. Kaspar Schlick wird in der Urkunde secretarius genannt, was er im J. 1422 auch gewesen ist. Untersucht man die Worte Kaspar Schlick secretario nostro, die zweimal vorkommen, näher, findet man, dass einmal das Wort secretario, das zweitemal die Worte secretario nostro auf Rasur von der Hand der Urkuude geschrieben sind. Man kanı auch noch entziffern, was früher auf der Stelle stand, da hiess es cancellario. Man bemerkt besonders an der zweiten Stelle deutlich das ursprüngliche $\mathrm{Ca}$ und l, welches nicht genügend ausradirt wurde ${ }^{1}$ ). Der Verfasser und Schreiber nannten Schlick in gewohnter Weise Kanzler und erst später hatte man sich besonuen, dass er im J. 1422 Sekretär gewesen ist: Die Urkunde ist also nicht im J. 1422 sondern jedenfalls erst nach der Ernennung Schlicks zum Kanzler, also nach dem Mai 1433 entstanden.

Da fällt jedoch etwas auf. Welchen Sinn hatte es nach dem J. 1433, also in einer Zeit, in der Schlick thatsächlich dem adeligen Stande angehörte, eine solche Standeserhebung zu fälschen und dieseibe nicht etwa in eine graue Vorzeit, sondern einfach 14 Jahre zurück zu versetzen. Eine Erklärung finden wir in einer Reihe von anderen Fälschungen, welche inverlich zusammenhängen und dieselbe Tendenz verfolgen wie die obeubesprochene.

Es sind die Urkuuden Altmann: Reg. 8799, 9407, 9543, 10341, $12148,12153$.

Am engsten ist mit dem gefälschten Freiherrendiplom eine vom 13. Juli 1433 aus Rom datirte Urkunde verknüpft ${ }^{2}$ ). In derselben beurkundet Sigismund, dass er Kaspar, Mathias und Wilhelm Schlick auf der Tiberhrücke zu Rittern geschlagen und verleiht ihnen eine Wappenvermehrung. Es werden die Verdienste des Kanzlers aufgezählt und ihm die Privilegien bestätigt. Die Urkunde ist wiederum kanzleigemäss, von einer nachweisbaren Kanzleihand geschrieben und mit einem echten Siegel (Heffuer, Taf. XIII. 96 n. 97) an schwarzgelben Schıüren versiegelt. Gegen den Hauptinhalt ist nichts einzuwenden. W ir wissen, dass der Ritterschlag stattgefunden hat, und eine bei dieser Gelegenheit verliehene Wappeuvermehrung ist ebenfalls anzunehmen ${ }^{3}$ ). Bedenklich sind folgende Sachen.

Von der gleichzeitig stattgefundenen Adelserhöhung wird kein Wort gesagt. Statt dessen werden dem Kanzler und seinen Brüdern

1) Vgl. Tafel I.

2) Original in Kopidlno IV. 4. Die Urkunde ist gedruckt bei Lünig RA. Spec. saec. 2. 1178 ff: Altmann macht zu der Urkunde ein Fragezeichen.

3) So hat auch Brisacher an dem Tage des Ritterschlages auf der 'Tiberbrücke eine neue Wappenzierde erhalten. 
ihre Briefe über „ihre Freiheit, Adel nnd Frhöhung“ bestätigt, also auf eine angeblich früher statttrefundene Adelserlöhung hingewiesen. Wir geben wohl' nicht fehl, wenn wir annehmen, dass hier auf die Fälschung vom J. 1422 Bezug genommen wird. Der Ton der Urkunde und die Art und Weise, wie die Verdienste des Schlick aufgezählt werden, stimmt mit jener Fälschung sehr überein. In einem Verzeichnis der Schlick'schen Urkunden aus dem 16. Jahrhuudert, wird eine Urkunde Sigismunds vom 31. Mai 1437 genannt, deren Inhalt in den kargen Worten des Verzeichnisses folgendermassen angedeutet wird: die Herren Caspar, Mathes und Wilhelm Schlick werden auf der Tiberbrücke zu Rittern geschlagen. Was soll also eine zweite Urkunde darüber vom 13 . Juli ${ }^{2}$ )? In der Urkunde wird gesagt, Schlick sei auf der Tiberbrücke vor allen anderen als der erste, oder wie es in einer anderen Fälschung heisst: „prae multis magnatibus" zum Ritter geschlagen worden ${ }^{3}$ ). In dem bereits erwähnten Briefe eines Egrers steht nichts davon, wir wissen auch, dass bei der Krönung und bei der Feierlichkeit der Verabreichung des Ritterschlages die Betheiligten streng nach den Ständen geordnet wurden ${ }^{4}$ ). Schlick wollte eben auch hier als der Nachkomme eines alten Adelsgeschlechtes erscheinen.

In der Urkunde wird der Kanzler Burggraf von Elbogen genannt. Doch Burggraf von Elbogen wurde er erst über ein Jahr später am 28. Sept. $\left.1434^{5}\right)$. Die Unterfertigung lautet: Ad mandatum domini imperatoris Petrus Kalde prepositus Northusensis. Die Urkunde ist vom 13. Juli und Kalde wurde erst am 26. Sept. für die durch den Rücktritt des früheren Inhabers frei gewordene Propstei zu Nordhausen präsentirt $\left.{ }^{6}\right)$.

So ist diese Urkunde ebenfalls eine Fälschung, die den wahren Sachverhalt der Standeserljebung Schlicks im Jahre 1433 entstellen und zugleich eine neue Bestätiguıg für die in das J. 1422 versetzte Fälschuvg bilden sollte. Ueber ihre Entstehungszeit können wir vorläufig sagen, dass sie jedenfalls wie die erste Fälschung nach dem 31. Mai 1433 verfasst wurde. Das J. 1433 oder die nä,hste Zeit darauf kann

1) Kopidlno VII. 14 vermuthlich ein Exemplar der Urkunde für einen der Brüder Kaspars, welches dann im Besitze der Familie geblieben ist.

2) Alle sonst erhaltenen Urkunden über den Kitterschlag sind von dem Krönungstage vom 31. Mai datirt.

3) Siehe Beilage VII.

4) Vgl. die Ordnung Ritter zu vordern und zu schlagen im ordinatio ingressus Friderici bei Pez, Scriptores II, 565.

5) Altmann 10848 .

6) Altmann 9685. Altmann verweist bereits auf diese Nichtübereinstimmung. 
man nicht recht annehmen. Wie hätte Schlick die Fälschung verwerten sollen in einer Zeit, wo der wahre Sachverhalt allgemein bekannt war. Es war unmöglich mit derselben aufzutreten, solange Sigismund lebte. Auch verweisen die Ungenauigkeiten in der Benennung Schlicks als Burggraf von Elbogen und Kaldes als Propst von Nordhausen auf eine spätere Entstehungszeit. Anderstheils können wir bei beiden Urkunden nicht allzu hoch hinaufgehen, denn wie gesagt, sind dieselben den :̈usseren Merkmalen nach vollständig kanzleigemäss.

In der zweiten Fälschung spricht nun der Kaiser prophetisch die Absicht aus, die Verdienste Schlicks mit höheren Würden noch zı belohnen ${ }^{1)}$. Es handelt sich nicht um eine Phrase der Arenga, die Worte stehen in der Narratio und giengen im J. 1437 in Erfüllung. Kurz vor seinem Tode erhob Sigismund den Kanzler in den Reichsgrafenstand. Sollte sich vielleicht die Andeutung der Fälschung auf diese neue Würde Schlicks beziehen?

Ueber die Erhebung berichten zwei feierliche Privilegien Sigismunds, ein deutsches vom 30. Oct. 1437, Prag und ein lateinisches von 1. Nov. 1437, $\operatorname{Prag}^{2}$ ). Sie sind uus in Originalen erbalten ${ }^{3}$ ), das erste ausserdem in einer Eintragung im Reichsregister 4 ). In den Urkunden wird die dem Kanzler vor Jahren geschenkte Herrschatt Bassano za einer Reichsgrafschaft erhoben, nach welcher er und seine Erben den Grafentitel führen sollen. Sie sollen als den Grafen ebenbürtig betrachtet werden und es wird ihnen eine volle Gerichtsexemption (so dass sie sich von nun an nur vor dem Kaiser verantworten sollen) und eine Befreiung von Abgaben verliehen.

Es sind diejenigen Urkunden, welche von den Schlick im J. 1486 den böhmischen Landrechten vorgelegt wurden. Die Stelle, auf welche sie sich dabei stützen wollten, lautet: „dass (die Schlick) nicht sollen geladen, geheissen oder furgefordert werden für unser und des reichs hofgericht noch vor keinerlei landgericht, es sei zu Franken, Schwaben, Sachsen oder anderswo noch für kein ander gericht in dem heiligen reiche oder in der cron zu Behem, sondern sie sollen ... zu recht stehen allein vor uns oder unseren nachkommen römischen kaisern und kunigen oder kuniginen zu Behem"5). Eine Befreiung von dem

1) (den wir) zu dem ersten ritter slugen und zu unserm obersten canczler wirdicklich erhuben und machten und in noch gnediclicher zu handeln vor uns haben.

2) Altmann 12148, 12153 als echt.

3) Kopidlno IV. $7,8$.

4) Reichsregister L. $59 / \mathrm{v}$ ff.

5) In der lateinischen Urkunde wird nur allgemein von Hof- und Landgerichten gesprochen. 
Hofgerichte und den deutschen Landrechten und Unterstellung unter persönliche Gerichtsbarkeit des Kaisers ist nichts aussergewöhnliches, es ist vielmehr eine zu erwartende Ergänzung der Begünstigungen der Urkunden ${ }^{1}$ ). Auffallend wäre nur die Einbeziehung Böhmens.

In Böhmen galt noch unter Wenzel als die Grundmaxime der Gerichtsverfassung, dass von den Landrechten niemand befreit werden kann, sie sind der "Gipfel des Rechtes" und selbst der König ist denselben in civilen Sachen unterworfen ${ }^{2}$ ). Von den Landrechten gab es keine Erocation noch Appellation, weder nach aussen noch im Lande. Auf diesen Standpunkt stellten sich auch die Stände im J. 1486: quando quidem sua regia maiestas et suae maiestatis antecessores reges Boemiae tali libertate non utebantur neque utuutur, ut ad indicium regni minus comparere deberent, quod etiam huiusmodi libertatem sua maiestas nemini dare potuit neque potest contra ritum et libertatem regai Boemiae. Dieser Be.chluss, der in die Landesordnung von 1500 als $\S 10$ aufgenommen wurde, ist selbstverständlich in einer Zeit der grössten Macht der Stände, für die vor allem die politische Seite der Frage massgebend war. Doch in den Zeiten des Interregnums, in den J. 1419-36 und in den J. 1439-53 war von einer Rechtssprechung keine Rede, die Gerichte waren nicht constituirt, im J. 1437 gab es keine ununterbrochene Tradition. Es ist zugleich die Zeit, in welcher sich in Deutschland neue Institutionen ausbilden. Obwohl mir kein zweites Beispiel bekannt ist und obwohl Sigismund den böhmischen Ständen im J. 1436 den Bestimmungen der Goldenen Bulle gemäss eine vollständige Unabhängigkeit vom Reiche in Bezug auf Gerichsbarkeit zugesichert hat ${ }^{3}$ ), wäre es vielleicht doch nicht ganz ausgeschlossen, dass er in einzelnen Fällen die in Deutschland so allgemein übliche Praxis auch als König von Böhmen in der böhmischen Gerichtsverfassung anzuwenden versucht hat.

Doch fassen wir den sonstigen Inhalt der Urkunden ins Auge. Besonders das lateinische Diplom ist ein merkwürdiges Document. Es ist ein Panegyricus, welcher jedoch schwerwiegende rechtliche Bestimmungen enthält. Der Kanzler wird mit den Scipiouen, Catonen und Fabriciern verglichen, zwischen ihm und dem Kaiser hätte ein Verhältnis bestanden, wie zwischen dem Sohn und dem Vater. Im Humanistenlatein und Humanistenstil verfasst, berichtet die Urkunde über

1) Vgl. Schröder III. Aufl. 539 ff.

2) Andreas von Dubé, Erläuterung der böhm. Landrechte 3. (Archiv Ceský III. +88).

s) Die Urkunde Sigismunds darüber Altmann 11240 gedruckt im Archiv Ceský III. 427.

Mittheilungen XXU. 
das Leben Schlicks mit der Breite einer erzählenden Quelle. „Quae omnia si rite perpenderimus, spectabilis comes Gaspar, quid est, quod non merearis, quid tibi conferre poterimus aut nobilitatis aut gloriae aut dignitatis, quod huiusmodi merita tua non superent! Profecto tibi tenetur ecclesia, tenetur imperium, tenentur regna nostra!“ wird am Schlusse der Lebensskizze gesagt, die jedenfalls auf Schlick selbst oder seine Angaben zurückgeht. Durch geschmacklose Schwulst unterscheidet sich die Urkunde wesentlich von gleichzeitigen Urkunden ähnlichen Inhaltes ${ }^{1}$ ) was ja vielleicht, falls es in der Urkunde vom J. 1422 Verdacht erregt hat, jetzt auf eine ganz besondere Bevorzugung des Kanzlers zurückzuführen wäre.

Wichtiger ist eine andere Uebereinstinmung. In den Urkunden wird wie in dem gefälschten Freiherrendiplom von der Herkunft des Kanzlers berichtet, es ist dieselbe Erdichtung. Der Vater Kaspars de quo sufficiens testimonium pridem recepimus - wäre aus einem edlen Rittergeschlechte und die Mutter Constanze eine Gräfin Collalto gewesen. Der Marggraf von Mautua, ein „Verwandter des Schlick“, hätte mit anderen italienischen Grossen den Kaiser, während seines Aufenthaltes in Italien, über ihre Verwandtschaft mit dem Kanzler unterwiesen - ita ut de sufficientia tuae nobilitatis atque propaginis nullus posset penitus dubitare. Die falschen Angaben der Urkunde vom J. 1422 , nach welchen Schlick bereits in seinen jungen Jahren eine wichtige Rolle bei Hofe und in der Politik gespielt hätte, werden ebenfalls wiederholt, und die Geschichte der Standeserhebung Schlicks wird in der Weise dargestellt, wie in den Fälschungen. Ja noch mehr, es wird Bezug genommen auf die letzteren. In dem lateinischen Privileg wird gesagt, Sigismund hätte Schlick in den Freiherrnstand erhoben iuxta continentiam nostrarum litterarum und diese Beförderung wird in die Zeit nach dem bellum Vissegradense et Brodense also in das J. 1422 verlegt. In der deutschen Orkunde heisst es: den wir vormals. vor viel jahren zu einem freien herren gemacht haben nach laut unserer kuniglichen majestätsbrief. Es wird also auch da die Standeserhebung in die Königszeit Sigismunds versetzt. Die Urkunde, von der in den beiden Diplomen gesprochen wird, ist folglich die Fälschung. vom J. 1422. Die wirklich stattgefundene Adelserhebung in Italien wird selbstverständlich verschwiegen und der Vorgang so dargestellt, wie in der vom 13. Juli 1433 datirten Fälschung. Die

1) Vgl. die als Formular ins Kanzleibuch D eingetragene Urkunde über die Erhebung in den Grafenstand auf fol. 72/v, oder etwa die Urkunde über die Erhebung der Grafen von Cleve zu Herzogen Altmann 2226, die Urkunden über die Fürstenerhebung der Cillier und a. 
letztere Urkunde wird nicht ausdrücklich genannt, aber die sachliche und zum Theil stilistische Uebereinstimmung mit den beiden Privilegien macht es zweifellos, dass sich dieselben ebenfalls auf diese Fälschung stützen ${ }^{1}$ ).

Man kann nicht annehmen, dass der Kanzler die Fälschungen dem Kaiser vorgelegt und eine Bestätigung derselben von ihm erlangt hätte. Ebenso unwahrscheinlich ist die Vermuthung, Schlick hätte den Inhalt der Fälschungen ohne das Wissen des Kaisers zu seinen Lebzeiten in echte Urkunden einschmuggeln können. Die Urkunden sollten von den Kurfürsten durch Willebriefe genehmigt werden und ihr Inhalt konnte nicht unbekannt bleiben. Durch eine solche Verunechtung wären die echten Diplome für den Kanzler wertlos geworden. Man wird dazu geführt die Urkunden über die Grafenerhebung Schlicks wenigstens in der vorliegenden Fassung ebenfalls als Fälschungen des Kanzlers zu betrachten, als Fälschungen, welche dieselben Tendenzen verfolgen wie diejenigen vom J. 1422 und 1433. Gefälscht sind diejenigen Stellen, welche sich auf die Spuria berufen und Nachrichten über die Herkunft, die Jugend und die ersten Standeserhebungen des Schlick enthalten. Doch nur die? Liegt etwa diesen Fälschungen eine echte Urkunde oder wenigstens eine wirklich erlassene Vertügung zu Grunde?

Die Herrschaft Bassano - cuius te pridem privilegio nostro dominum fecimus - wird zu einer Reichsgrafschaft erhoben, nach der die Schlick den Namen führen sollen. Ueber die Sehenkung von Bassano an Kaspar Schlick besitzen wir drei Urkunden. Die eigentliche Schenkungsurkunde (die uns nur in einer Bestätigung Friedrichs im Reichsregister 0.164 erhalten ist), ist vom 21. Aug. 1431 und offenbar aus denselben Bestrebungen entsprungen, wie die uns bekannt gewordenen Fälschungen ${ }^{2}$ ). Es wird wiederum ron der Abstammung des Schlick vou den Markgrafen von Treviso erzählt, Kaspar wird als nobilis und generosus bezeichnet (im J. 1431), er hätte seinen alten Adel aliarum gratiarum titulis vermehrt. Es wird alles das vorausgesetzt und im Auszuge auch gesagt, was in dem gefälschten Freiherrendiplom ent-

1) Die Urkunde vom J. 1437 Nov. 1. Die Urkunde vom J. 1433 Juli 13. ubi te eciam in ponte Tiberis more ve- (den wir) als einen verdienten terum equo insidentem pre multis $\mathrm{man}$ mit unsere eigen hand nach emmagnatibus eligendo inter mili- pfahung unser keiserlichen cron an dem tes primum cinximus et militari heiligen pfingstagnechst vergangen uffder honore tamquam bene meritum Tiberbruck under allen andernder dignum iudicavimus.

2) Beilage II. Altmann 8799 (Fälschung §). ein grosse menig gegenwertig was, $z$ u dem ersten ritter slugen. 
halten ist, die Gründe, welehe gegen den Inhalt der letzteren angeführt wurden, haben auch hier ihre Geltung. Die Annahme einer freien Stilisirung Schlicks kann ebensowenig in Betracht kommen, wie bei den übrigen Urkunden. Die gefälschte Adelserhebung ist nach dem J. 1433 entstanden. Schlick hätte bereits in J. 1431 in eine echte Urkunde alles hineinstilisirt, weshalb er einige Jahre später eine eigene Urkunde gefälscht hat? Kann man es etwa hier durch freie Fassung erklären, wenn sich Schlick zwei Jahre früher dem Adel zurechnet, bevor er dazu berechtigt war? Wir haben bei der Behandlung der in das J. 1422 versetzten Fälschung hervorgehoben, dass der Inhalt vermuthen lässt, dass sie erst nach dem J. 1433 entstanden sein kann, denselben Inhalt finden wir in der Schenkungsurkunde von Bassano. Wenn die Orkunde vom Kanzler nur verunechtet wurde, so geschah das nicht im J. 1431, sondern nach dem J. 1433, falls Bassano von dem Kaiser an Schlick geschenkt und eine Urkunde darüber ausgestellt wurde, ist es nicht die vorliegende. Doch sind nicht eben die Verunechtungen eine Voraussetzung für den sonstigen Inbalt der Schenkung?

Bassano stand im Mittelalter unter der Herrschaft der Ezzelinen, von 1260-1319 unter der Obergewalt von Vicenza. Im J. 1319 von Can Grande erobert, musste es 19 Jahre lang die Scaliger als Herren anerkennen. Im J. 1339 folgten denselben die Carraresen, im J. 1388 die Visconti. Im J. 1404 sah sich Katharina Visconti gezwungen die Stadt und das Gebiet an Venedig abzutreten, von da blieb Bassano im Besitze der Republik ${ }^{1}$ ). Natürlich haben die Schlick in Bassano nie ein Haus besessen. Für die Schenkung war kein über ganz allgemeine königliche Verleihungsrechte hinausgehender Rechtstitel vorhanden, man könnte dieselbe höclıstens als eine recht illusorische Kriegsrepressalie gegen die Venetianer auffassen. Bekanntlich wurde im Jahre 1431 der Krieg mit Venedig wieder aufgenommen. Aus demselben Jahre ist die Urkunde datirt. Sigismund schloss ein Bündnis mit Philippo Maria Visconti, der in dem Kriege unter anderem jene Gebiete wieder zurüekerobern hoffte, welche seine Mutter an die Repulik verloren hatte. Und derHerzog von Mailand hätte seine Ansprüche an die Beherrscherin der Brenta, an das für den Handel so wichtige Bassano so ohne weiters an einen Protonotar abgetreten?

Auf die Schenkung ron Bassano beziehen sich noch weitere zwei Urkunden. Eine derselben vom 31. Mai 1433 Rom, in einer Eintragung im Reichsregister K. 232 erhalten, ist eine allgemeine Bestätigung der Schlickschen Privilegien, von denen nur dasjenige über Bassano aus-

1) Vgl. Brentari. Storia di Bassano e del suo territorio. Bassano. 1884. 
drücklich hervorgehoben wird: et maxime donationem et concessionem de castro et dominio Bassani 1). Am 4. Juni wurde der fünfjährige Waffenstillstand mit Venedig abgeschlossen ${ }^{2}$ ). Die Urkunde dürfte also folgenden Sinn haben: wenn auch der Frieden mit der Republik, die sich im Besitze von Bassano befindet, demnächst provisorisch hergestellt sein wird, bleibt es bei der Verleihung des Gebietes an den Kanzler.

Die dritte Urkunde - im Reichsregister K. 233 - ist vom 1. Mai 1434 ${ }^{3}$ ): Sigismund verspricht dem Kanzler und seinen Erben, dass ohne ihre Einwilligung die ihnen geschenkte Stadt und Herrschaft von Bassano nie wieder an die Venetianer zurückgegeben werden darf, auch dann nicht, wenn er eine Vereinbarung mit denselben schliessen würde: quod si nos aut successores nostros Romanorum imperatores seu reges cum illustri dominio Venetorum contingeretur aliquam inire concordiam . .4). Diese concordia, von der Urkunde vorausgesagt, ist ein Jahr später in dem Bündnisse Sigismunds mit Venedig gegen den Herzog von Mailand thatsächlich zu Stande gekommen. Das ist verdächtig und der Verdacht wird bestätigt, wenn wir die Vereinbarungsurkunde zwischen dem Kaiser und den Venetianern durchlesen ${ }^{5}$ ). In derselben werden Rechts- und Besitzansprüche beider Contrahenten genau geregelt. In Bezug auf Lombardische Besitzungen wird festgesetzt, dass die Venetianer alles diesseits der Adda behalten sollen. Und: serenissimus dominus teneatur conferre ipsi dominio Venetiarum titulos perpetuos ac facere et dare in forma debita et solemni privilegia de omnibus civitatibus, terris, castris et locis quibuscunque spectantibus ad imperium, quae et quas ipsum dominium in presenti possidet seu tenet, excepto quantum de civitatibus Verone et Vicencie ... Man vergleiche damit die Worte dès Versprechens Sigismunds: quod eidem dominio nequaquam dabimus titulos aliquos de prefato castro et dominio.

Von den Ansprüchen Schlicks, auf welche bei einem solchen Vertrage Rücksicht zu nehmen, der Kaiser urkundlich gelobt hatte, wird kein Wort gesagt. Das ist umso bezeichnender, als die Prätensionen des Brunoro della Scala, dem Sigismund seine Anrechte auf das ebenfalls seit dew J. 1404 im Besitze der Venetianer befindliche Verona und Vicenza in den J. 1412 und 1433 bestätigt hat6), ausdrücklich

1) Beilage III.

2) Altmann 9478 .

s) Altmann 10341 als echt.

4) Siehe Beilage V.

5) Zuletzt gedruckt in RA. XI, $5 \& 8$.

6) Altmann 176 und 9487 . 
constatirt und als aus dem Vertrage ausgenommen bezeichuet werden. Venedig wurde mit den lombardischen Besitzungen vom Kaiser investirt und behielt ruhig Bassano. Und was wir in dem Vertrage finden, das gilt auch für die langen Verhandlungen in den J. 1433-35 zwischen dem Kaiser und den Venetianern. Wir sind über dieselben gut unterrichtet $^{1}$ ). Die Venetianer suchten den Kanzler für Geld zu gewinnen, damit er bei dem Kaiser ihnen Günstiges erwirke, was auch gelungen ist $^{2}$ ). In den Anweisungen der Republik an ihre Emissäre wird von dieser Bestechung öfters offen gesprochen. Áber nie werden die Ansprüche des Kanzlers auf Bassano erwähnt oder nur eine Andeutung auf sie gemacht3). Es ist zweifellos, in Venedig wusste man nichts von denselben.

Schlick hat also die ihm verliehenen Rechte auf Bassano aufgegeben oder dieselben waren nicht vorbanden. Dass das erste nicht der Fall war, bezeugt das Grafendiplom vom J. 1437.

In demselben Jahre wurde das Bündnis der Venetianer mit dem Kaiser erneuert. Wir kennen die Instructionen, welche Marc Dandolo für die Verhandlungen mit Sigismund von der Republik erhalten hat ${ }^{4}$ ). Die Anweisungen, welche Venedig seinen Abgesandten mitzugeben pflegte, lassen nie an Ausführlichkeit zu wünschen übrig, es wird nichts vergessen. Mit Brunoro della Scala wollte man ein Abkonmen treffen, man bot ihm 1000 Dukaten für das Fallenlassen seiner Ansprüche, er wollte 2000. Von dem Kanzler kein Wort ${ }^{5}$ ). Und Sehlick führte selbst die Unterhandlungen. Er correspondirte diesbezüglich mit Barbaro, welcher ursprünglich die Gesandtschaft zum Kaiser führen sollte, dann durch Krankheit abgehalten war. In den Briefen finden wir keine Erwähnung von Bassano ${ }^{6}$ ). Auch sonst nirgends. Erst unter Friedrich schreıbt der Kanzler einmal an den Herzog von Mailand, man möchte ihm doch irgend eine Besitzung, eine Burg in Italien verschaffen ${ }^{7}$.

Im Juli wurde das Bündnis mit Venedig erneuert und die Republik bekam das Reichsvicariat über alle Gebiete, die sie besass diesseits der

1) Vgl. RA. XI. XXI ff, und die einschlägigen Actenstücke.

2) Vgl. RA. XI. XLIV.

s) Vgl. RA. XI. 152, 343, 344, 347.

4) Verci Storia d. marca Trivig. Doc. 19. 151.

5) Daselbst.

6) Cod. der Wiener Hofbibl. 5667. 15 ff:

7) Der Brief Schlicks an Nicolaus de Arzimboldis 1443 Sept. 16. Grätz und an Albericus Maletta, 1443 Sept. 17. Grätz im Cod. lat. 5311 der Münchner Hof bibliothek fol. 211 und $211 / \mathrm{v}$. 
Etsch ${ }^{1}$ ). Schlicks angebliches Besitzanrecht auf Bassano ist weder im J. 1435 noch im J. 1437 weder berücksichtigt noch überhaupt zur Sprache gekommen, was sicher der Fall gewesen wäre, hätte es bestanden.

Ich recapitulire: die Schenkung von Bassano steht in einer sonst höchst verdächtigen, mindestens stark verunechteten Urkunde, ist an und für sich unwahrscheinlicb und wird in den Verhandlungen, die über eine Regelung des Venetianischen Besitzes in der Lombardei stattgefunden hatten, nie erwähnt, von dem Kanzler nie geltend gemacht. Es drängt sich der Schluss auf, dass die Schenkuugsurkunde nicht nur in ihrer vorliegenden Fassung von Schlick verfälscht, sondern dem ganzen Inhalte nach eine Fälschung ist. Dann natürlich auch die Bestätigungsurkunden.

Wir werden uns erinnern: in dem gefälschten Adelsdiplom werden den Schlick angebliche Anrechte auf die Besitzungen der Markgrafen von Treviso bestätigt. Sollte hier etwa ein imaginärer Rechtstitel für die aus der Luft gegriffene Verleihung geboten werden? Noch deutlicher bezeugen eine ähnliche Absicht andere Worte der Urkunde: die Schlick sollen das Recht haben, nicht nur Adelsgüter ,immo et bona comitatum" zu besitzen ${ }^{2}$ ). Zwecklos und unverständlich in einer Urknnde vom J. 1422 bekommt nun die Stelle eine Bedeutung, denn im J. 1437 wurde Bassano zu einer Grafschaft erhoben.

So stützen sich die Urkunden über die Erhebung des Kaspar Schlick in den Reiehsgrafenstand, sowohl in Bezug auf das, was in denselben über die Herkunft, Jugend, Verdienste, erste Standeserhebungen des Kanzlers gesagt wird, als auch in Bezug auf die Verleihung jenes Besitzes, welcher der Standeserhebung zu Grunde gelegt wurde, auf Fälschungen. Damit werden aber auch diese Diplome als Fälschungen nachgewiesen. Zu vermuthen, dass der Kaiser eine Reihe von so tief einschneidenden unechten Urkunden Schlicks acceptirt, dieselben in solenner Weise bestätigt und als Ausgaugspunkt und Grundlage für eine ganz ungewöhnliche Auszeichnung des Kanzlers genommen hätte, wäre absurd. Ebensowenig können wir an eine Umarbeitung Schlicks denken, da die Schenkung von Bassano einen integrirenden Theil der Privilegien bildet.

Die Urkunden über die Erhebung des Kanzlers in den Reichsgrafenstand sind der Mittelpunkt und wie es scheint Endzweck der

1) Altmann 11883 und 11926 .

s) Beilage I. 
besprochen Fälschungen. Jedenfalls münden da die Besitzprivilegien. über Bassano ein. Es wurde gesagt, dass ohne das gefälschte Freiherrendiplom die Schenkung vom J. 1431 kaum glaubwürdig erschienen wäre. Ebenso wäre für die Grafenerhebung die einfache in Gesellschaft von vielen anderen im J. 1433 erfolgte Nobilitirung ein gar zu dürftiges Vorspiel gewesen. War dies der einzige Grund, warum Schlick seine Promovirung in den Freiherrenstand um 11 Jahre zurückdatirt und den Bericht über die Standeserhebung vom J. 1433 verfälscht hat? In allen vier Fälschungen, welche die Standeszugehörigkeit Schlicks bestimmen und ausserden in der Schenkungsurkunde von Bassano wird mit Betonung über die adelige Abstammung des Kanzlers berichtet. Wohl beginnt der Adel bereits durch den Zerfall der alten Institutionen in eine neue Stellung gedrüngt, Wert auf seine Descendenz zu legen und sechs- und achtgliedrige Ahnentafeln, die noch kein Rechtserfordernis sind, werden beliebt. Dazu kommt die antiquarische Prahlsucht, die damals nicht entstanden, aber viel mehr gepflegt wurde als früher. Trotz alle dem dürften rein genealogische Fälschungen doch erst aus dem 16. Jahrhundert nachzuweisen sein. Vou Schlick können wir vielleicht am wenigsten vermuthen, dass er in die Fälschungen Angaben aufgenommen hätte, welche so leicht Veranlassung zur Verdächtigung der Urkunden bieten konnten, hätten dieselben nicht einen anderen reellen Wert für ihn gehabt. Im letzten Reichsregister Sigismunds ist auf S. 61 eine Urkunde vom 25. Juli 1437 für Schlick eingetragen, die einen merkwürdigen Inhalt hat. Es wird dem Kanzler seine adelige Abstammung bestätigt "dorumb wir ihn auch vor etlichen jahren zu einem freiherren und banirherren gemacht haben " ${ }^{1}$ ). Diese Adelsbestätigung erfolgt deshalb, damit die Gattin Schlicks die Herzogin Agnes von Oels „hinfur solchs heirats nicht entgelde, sunder irer furstlichen geburt und wirdikeit gebrauch und geniss, wie wol das in keiserlichen rechten clar begriffen und geschrieben ist, wo eine furstinn einen ritter nimd und nicht aus dem grad des adels greiffet, dass sie dadurch an iren wurden nicht genedert wirt, sunder der gebrauchen sol an allen enden." Es muss nicht bewiesen werden, dass die Urkunde eine Fälschung ist. Die adelige Abstammung des Kanzlers, also diejenigen Angaben der Fälschungen, welche zuerst den Verdacht erregten, werden hier in einer eigenen Urkunde confirmirt. Wir hätten auch von dieser Fälschung ausgehen können, so ist sie ein neuer Nachweis für das Gesagte.

1) Beilage VI. Altmann 11903 echt. 
Die Heirat des Schlick war eine Mesalliance. Wir wissen, die Frau wurde eine Standesgenossin des Mannes, falls sie einen Untergenossen genommen hatte ${ }^{1}$ ). Und das war der Kanzler bis zu einem gewissen Grade, trotz der Adelserhebung vom J. 1433. Abgesehen davon, dass man in Deutschland nicht einmal den Ritterschlag, den Sigismund in Rum so reichlich ausgetheilt hatte, anerkennen wollte ${ }^{2}$ ). Die Ebenbürtigkeit, die sonst unter Edlen in allgemeinen bestanden hat, war für eine Reihe von rechtlichen und gesellschaftlichen Fragen nur dann vorkanden, wenn beide Parteien der Geburt nach dem Adel angehörten ${ }^{3}$ ). Das war bei Schlick, dem Sohne eines Bürgers und einer Bürgerin, nicht der Fall. Wäre jedoch, wie die Fälschungen behaupten, sein Vater aus einem edlen Rittergeschlechte, seine Mutter eine Gräfin Collalto gewesen, war der Kanzler ein einwandsfreier Herrengenosse und die Fürstin Agnes hätte durch ihre Heirat thatsächlich nicht aus dem Grade des Adels gegriffen. Und so wird es auch in den Fälschungen betont. In dem Freiherrendiplom wird er zu einem Magnaten gemacht, obwohl er edler Herkunft ist ${ }^{4}$ ) und in dem lateinischen Diplome über die Grafenerhebıng finden wir am Schlusse des Berichtes über die Herkunft des Kanzlers die bereits einmal angeführten Worte: ita ut de sufficientia tuae nobilitatis atque propaginis nullus posset penitus dubitare.

So verfolgen die besprochenen Fälschungen zweierlei Zweck, es waren die Krücken, auf welche sich die gefälschte Erhebung in den Reichsgrafenstand stützen sollte und sie sollten die Ehe mit Agnes von Oels als ebenbürtig erscheinen lassen. Daraus ergibt sich, dass sie nicht gar zu lange Zeit vor oder erst nach der Verheiratung Schlicks, welche etwa im Frühjahr 1437 erfolgte, anderstheils vermuthlich gleichzeitig mit den vom letzten October und 1. November desselben Jahres datirten Urkunden über die Grafenerhebung entstanden sind. Das wahrscheinlichste dürfte sein, dass sie erst nach dem Tode Sigismunds (9. Dec.) hergestellt wurden.

1) Vgl. Schröder III. Aufl. 757 ff., daselbst auch die Literatur über die Ebenbürtigkeit im späteren Mittelalter.

2) Aschbach IV. 118, Anm. 29.

3) Ich verweise bei dieser Gelegenheit auf den interessanten Adelsbrief für. Konrad Beyer von Boppard vom J. 1421 Juni 5 (Altmann 4543), in dem gesagt wird, dass viele Pfründen, welche vier edle Ahnen verlangen, nicht besetzt werden können und das Hofgericht über Adelige oft nicht vollzählig ist, weil der Adel abgenommen und sich durch Missheiraten vielfach vermindert hat.

4) Die Worte sane quamvis... 
Es frägt sich nun, ob die Ueberlieferung der Urkunden diesem Ergebnisse nicht widerspricht. Es wurde gesagt, dass die Fälschungen über die Standeserhebungen im J. 1422 und 1433 in kanzleigemässen Originalen erhalten sind. So auch die Diplome über die Grafenerhebung ${ }^{1}$ ). Die Schrift stammt von einem Kanzleischreiber, welcher 乙. B. die beiläufig gleichzeitigen Urkunden Altmann 11895, 11914 u. a. geschrieben hat und auch in der Kanzlei Albrechts beschäftigt wurde ${ }^{2}$ ). Die in die J. 1422 und 1433 gesetzten Standeserhebungen sind, wie ein genauer Vergleich unter Heranziehung anderer Beispiele lehrt, von einer und derselben Hand geschrieben, die mit der früher besprochenen ähnlich, aber nicht identisch ist. Es ist ebenfalls die Haudschrift eines Kanzleischreibers, der lange Zeit in der Kanzlei thätig war. Er besorgt in den J. 1418-32 Eintragungen in Register, schreibt in den folgenden Jahren eine grosse Anzahl von Urkunden ${ }^{3}$ ) und wird ebenfalls vou der Kanzlei Albrechts übernommen ${ }^{4}$ ). Da wir mit beiden Händen noch ferner $\mathrm{zu}$ thun haben werden, wollen wir sie mit $a$ und $b$ bezeichnen. Und nun die Unterfertigungen. Soweit ich im allgemeinen für die Zeit Sigismunds die Sache verfolgen kounte, fand ich die Resultate Lindners bestätigt: eine bestimmte Regel ist nicht vorhanden, es kommen eigenhändige Unterfertigungen vor, aber daneben und wahrscheinlich in der Mehrzahl der Fälle wurden sie vom Schreiber des Textes geschrieben, manchmal weisen sie eine andere Hand auf und sind doch nicht eigenhändig: es unterschrieb z. B. für den Kanzler einer der Protonotare, der gerade anwesend war. Das Freiherrendiplom trägt die Unterfertigung des Michael Priest5). Es würde gegen unsere Beweisführung sprechen, falls dieselbe eigenhändig wäre, da Michael in den letzten Jahren der Regierung Sigismunds nicht in der Kanzlei beschäftigt war. Eine authentische von Priest zugestandene Unterfertigung aus dem J. 1422 trägt das noch zu erwähnende Falsum für den Herzog von Lauenburg ${ }^{6}$ ). Ein Blick auf diese und diejenige unserer Urkunde besagt, dass sie von verschiedenen Händ $n$ geschrieben wurden. Dagen finden wir die Schrift der Unterfertigung des Frei-

1) Siegel Heffner, Taf. XIII. 96 und 97, echter Registraturvermerk.

2) Taf. II. 1. Zu Vgl. KU. VI, 6a. Die Urkunden im Wiener Staatsarchiv 1438 Mai 28 Lehenbrief für Sigm. Leuprechtinger, 6. Oct. Zollfreiheit für die Herren von Stahrenberg $u$. a.

s) Beispiele aus dem Wiener Staatsarchiv. Altmann 9346, 9907 aus dem J. 1433, 12155 ausdem J. 1437 u, a.

4) 1438 Oct. 14. Lehnbrief für Herzog Friedrich von Oesterreich im Wiener Staatsarchiv.

5) Facsimile auf S. 75.

6) Kaiserurkunden in Abbildungen V. 18. 
herrendiploms auf anderen Urkunden, deren Text ebenfalls von der Hand b geschrieben wurde und wo die Unterschriften einen anderen Namen tragen ${ }^{1}$ ). Die Unterfertigung stammt also wahrscheinlich von der Hand des Textschreibers, was durch Schriftvergleichung auch bestätigt wird $^{2}$ ). Dasselbe gilt von der Unterfertigung Kaldes auf der
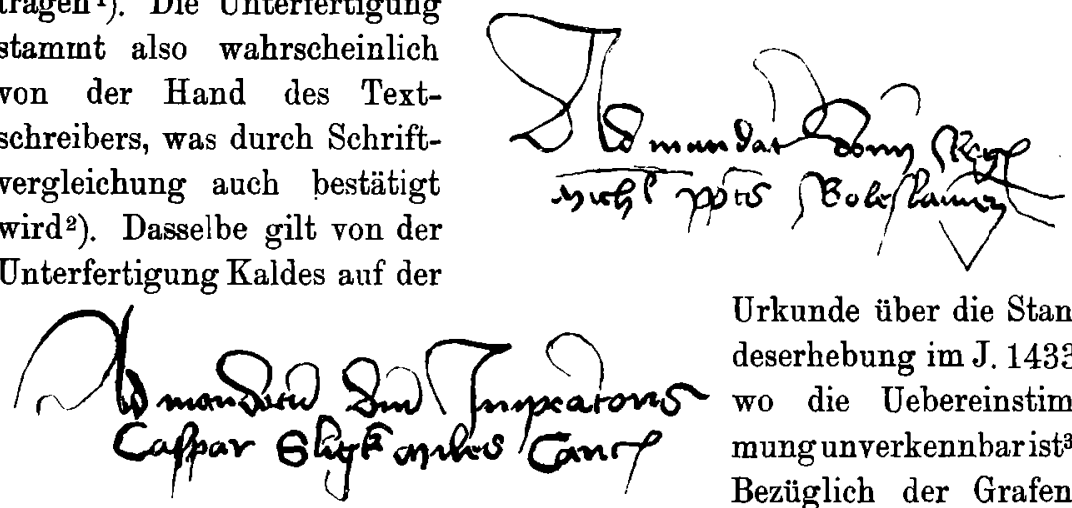

Urkunde über die Standeserhebung im J. 1433, wo die Uebereinstimmung unverkennbar ist ${ }^{3}$ ). Bezüglich der Grafendiplome konnte ich auf Grund des mir zu Gebote stehenden Materials nicht feststellen, ob die Unterfertigung Hechts eigenhändig ist, oder etwa vom Schreiber a. Es liegt auch nichts daran, denn Hecht fertigt sowohl im J. 1437, als auch in der Kanzlei Albrechts. Wichtig ist, dass sowohl der Text als die Unterfertigungen der zurückdatirten Fälschungen von einem Schreiber herrühren, der in der Kanzlei in jener Zeit nachzuweisen ist, in welche wir aus inneren Merkmalen die Entstehung der. Urkunden versetzt haben.

Die Privilegienbestätigung vom 31. Mai 1433, die Urkunde über den Besitz von Bassano vom J. 1434, die Bestätigung der adeligen Herkunft des Schlick vom J. 1437 und die lateinische Urkunde über die Erhebung in den Reichsgrafenstand sind in den Reichsregistern eingetragen. War unsere Beweisführung betreffs der Entstehungszeit dieser Urkunden richtig, können dieselben nicht in der Zeit, aus welcher sie datirt sind und folglich auch nicht an den Stellen, wo sie hingehören, oder nur als Einschiebungen registrirt worden sein. Solche Einschiebungen kamen vor und Seeliger macht sie geradezu zur Regel. "Gerade der Umstand wohl, dass gleich datirte Stücke zu sehr verschiedenen Zeiten in der Registratur einliefen, veranlasste den Beamten, die Regesten nicht regelmässig in örtlicher Aufeinanderfolge, sondern sprungweise einzutragen, einzelne Blätter oder Blätterreihen anfangs leer zu lassen und sie erst später theilweise oder ganz zu beschreiben ${ }^{4}$ ).

1) So z. B. die Fertigung Schlicks vom Geleitbriefe für österr. Räthe vom 21. Dec. 1433 im Wiener Staatsarehiv oben facsimilirt. Man vergleiche etwa das charakteristische Schluss-s in ppts, Impratoris, miles.

2) Man vgl. das $d$ oder dieselbe Hand $b$ auf Tafel III. 2, wo sie cursiv schreibt, so dass sich die Probe besser zum Vergleiche eignet. s) Taf. III. I.

4) Die Registerführung etc. Mitth. d. Instituts Ergbd. 3. 342. 
Doch in den Registerbüchen Sigismunds kommen die ausgefüllten oder unausgefüllten Lücken zum mindesten nicht regelmässig vor. Ausgenommen das Register E, welches zu Zeiten der grossen Reisen Sigismunds überhaupt unordentlich geführt wurde. Aber bereits im zweiten Registerbuche und in allen folgenden wurden die Urkunden, in der Regel eine grössere Anzahl auf einmal ${ }^{1}$ ), in continuo, Stück an Stück gereiht, eingetragen. Raum für Nachzügler wurde am Schlusse der einzelnen Jahre gelassen, sonst aber nur ausnahmsweise und wahrscheinlich nur dann, wenn ein Grund vorlag, wenn sich etwa die Eintragung eines bestimmten Stückes verzögert hat oder unterbrochen wurde. Häufigere Nachträge finden wir erst im Reichsregister J wieder, der Aufenthalt Sigisnunds in Italien mochte die Buchung in Unordnung gebracht haben. Im folgenden Register, welches die J. 1433-35 umfasst und in welchem die ersten zwei der oberwähnten Schlickschen Urkunden zu suchen sind, kehrte man zur alten Ordnung zurück; eine Lücke ist auf fol. 94, auf fol. 53 wurde eine Urkunde am Rande nachgetragen und auf fol. 121, 208 und $\left.208\right|^{v}$ wurden kurze Nachträge in den Raum zwischen zwei Eintragungen eingezwängt, sonst ist aber der Band fortlaufend geschrieben worden. Auf fol. 19, wo dem Datum nach beiläufig die erste der genannten Urkunden registrirt werden sollte, finden wir folgende unten am Rande nachgetragene Notiz: Item data est una confirmacio domino Gaspari Sligk cancellario, que est registrata in fine huius registri. Datum in die coronationis. Una alia littera, sicut imperator sibi promisit et pollicitus est non inire concordiam cum Venetis nisi etc. Die Urkunden selbst sind thatsächlich auch am Schlusse des Registers $\left.{ }^{2}\right)$. Es folgt denselben zwar noch eine Eintragung, eine Privilegienbestätigung für Waldsassen, doch aus dem Datum ersehen wir, dass dieselbe ebenfalls nachgetragen wurde ${ }^{3}$ ). Es ist auch auffallend, dass es gerade ein Privileg für jenes Kloster ist, zu welchem der Kanzler stets in Beziehungen stand und von dem er Güter um Schleuderpreis erworben hat. Die Nachträge sind von jener Hand, welche alle Eintragungen im Reichsregister in den letzten Jahren Sigismunds besorgt und auch noch in den ersten Monaten der Regierung Albrechts registrirt.

1) Vgl. die Ausführungen Lechners über dieselbe Praxis in der Kanzlei Friedrichs, Mitth. des Instituts 20. 52.

2) Fol. 232, 233.

3) Die vorangehenden Daten sind: 1435, 4./V., 7./V., 30./IX., 12./X., 26./X., 3./XII., 4./XII., 5./XII., dann Nachträge 1435, 3./LI., 1434, 25./VII., 1435, 22./XII., dann die Schlickschen Urkunden 1433, 31./V. und 1434, 1./V., dann die Urkunde für Waldsassen 1434, 6./LX. 
Aehnlich verhäit es sich mit den zwei anderen gefälschten Diplomen. Es wäre gar nicht unmöglich, dass die Urkunde über die Grafenerhebung in ganz regelrechter Weise an der ihr der Zeit nach zukommender Stelle eingetragen worden wäre. Sie ist vom 31. October datirt, der Kaiser starb am 9. December und wir wissen, dass die Buchung nicht, sogleich sondern manchmal erst nach längerer Zeit ruckweise erfolyte. Wir finden jedoch wiederum das gefälschte Privileg zugleich mit dem Falsum über die adelige Herkunft des Kanzlers als Nachtrag, als die letzten Stücke des Registers $L^{1}$ ). Da die vorangehenden Eintragungen bis zum 4. December reichen und wohl nicht gleich an dem Datumtage eingetragen wurden, müssen wir annehmen, dass die Registrirung der Schlickschen Urkunden erst nach dem Tode Sigismunds erfolgte. Es scheint dafür noch ein anderer Grund zu sprechen. Die Registerbände tragen eine gleichzeitige Foliirung und zwar wurden entweder die Blätter nur so weit gezählt, als die Eintragungen reichen (E, F, H, L), oder auch die leeren Blätter darüber hinaus $(J)$ und bis zum Schlusse $(K)$. Die Foliirung erfolgte nicht successive mit den Eintragungen, da sie stets im ganzen Bande von einer Hand ist, auch da, wo in den Eintragungen die Hände wechseln. Es liegt die Vermuthung nahe, dass wenigstens in jenen Bänden, in welchen die Foliirung so weit reicht, wie die Eintragungen, die Blätter dann gezählt wurden, als man den Band abschloss und als man etwa daran gieng ein Verzeichnis der eingetragenen Urkunden herzustellen. So erweisen sich im Register F drei Urkunden, welche auf den letzten nicht mit alten Zahlen versehenen Blättern eingetragen wurden, dem Datum und theils auch der Schrift nach als Nachträge. Im Register K entfällt dieser Anhaltspunkt, da die Blätter bis zum Schlusse gezählt wurden, im Register L jedoch reicht die Foliirung nur bis fol. 59, die Schlickschen Urkunden stehen auf ungezählten Blättern und dürften in einer Zeit eingetragen worden sein, als man den Band bereits ausser Gebrauch gesetzt hatte.

So spricht die Ueberlieferung dieser Urkunden nicht nur nicht gegen unsere Ausführungen, der Kanzler sorgt sonst, dass die Urkunden, die er vom Kaiser erhielt, 'gleichzeitig registrirt werden und bei den wichtigsten hätte er so lange gewartet?

Und ferner: bis zum J. 1442 wissen die Zeitgenossen nichts von der Erhebung Schlicks in den Reichsgrafenstand, bis zu dem genannten Jahre macht er selbst von ihr absolut keinen Gebrauch. In keiner Urkunde, welche aus der Kanzlei Sigismunds nach dem angeb-

1) Fol. 59-61. 
lichen Erhebungstage für Schlick ausgestellt wurde ${ }^{1}$, in keiner Urkunde aus der Kanzlei Albrechts wird er Graf genannt oder Herr von Bassano2). Um Albrecht hatte sich Schlick nicht geringe Verdienste erworben. Die Rede, in welcher er seine Wahl in Prar empfohlen hat, gehört zu den glänzendsten oratorischen Leistungen des Zeitalters. Albrecht zeigte sich erkenntlich und schenkte dem Kanzler die Herrschaft Weisskirchen in Ungarn. Nach dieser Herrschaft wird Schlick in Urkunden und erzählenden Quellen: K. S. Ritter, Herr zu Weisskirchen genannt. So kennen ihn Fremde und Freunde. Ueber die Schenkung Albrechts ist uns eine feierliche Urkunde rom J. 1438, April 30 erhalten $^{3}$ ). Die Urkunde ist erht, der ganze Inbalt spricht dafür. E's wird in derselben gesagt, Dankbarkeit hätte den König bewogen, den Kanzler durch diese Schenkung auszuzeichnen, ausserdem aber eine andere Ursache. Auf dem Todtenbette hätte Sigismund seinen Schwiegersohn gebeten, er möge dafür sorgen, dass der Kanzler, der ihm ein treuer Diener war, dafür Dank und eine Entlohnung erhalte. Diese Worte wären schwer verständlich, wenn Sigismund den Kanzler, ausser den vielen anderen Begünstigungen und Schenkungen der letzten Monate, auf die wir noch zu sprechen kommen, vor kurzen zum Reichsgrafen gemacht hätte. Und Albrecht fasst diese letzte Verfügung so auf, dass er dem Kanzler einen Besitz in Ungarn schenkt. In der Urkunde werden ebenfalls ausführlich die Verdienste und der Lebenslauf Schlicks geschildert und diese Schilderung ist eine vernichtende Kritik der Fälschungen. Da steht kein Wort von den übergrossen Diensten, welche der Kauzler bereits in seiner Jugend Sigismund erwiesen haben soll und seine Verdienste in Italien und späterer Zeit werden auf das richtige Mass reducirt, er war ein steter Begleiter des Kaisers in guten und schlechten Zeiten und hatte sich während der Verhandlungen mit den Hussiten und von seiner Sendung nach dem Norden an als ein überaus geschickter Diplomat erwiesen, eine Auffassung, wie sie uns durch alle unver-

1) Wie früher nennt er sich K. S. Ritter oder K. S. Ritter, Burggraf zu Eger und Elbogen. Vgl, die Urkunden Altmann 12154, 12168, 12176.

2) Vgl. die Urkunden Albrechts für Schlick von 1437, Dec. 11. ILünig RA. Sp. saec. II. 1187), 1438, Sept. 21. (Reichsregister M. 17./v), Sept. 29. (Daselbst 18), Oct. 16. (Daselbst 48/v), 1439, Juni 29. (Daselbst 63/v), Sept. 7. (Daselbst 70/v), Sept. 22. (Daselbst 72).

3) Beilage VIII. Original in Kopidlno X. 3. In der Urkunde wird dem Kanzler das Schloss Uivár (Neuhäusel) verliehen. Weisskirchen ist heute ein Dorf nicht gar zu weit von Neuhäusel. Dass hier beides identificirt wird, ist durch Urkunden Friedrichs bezeugt, in welchen Schlick: Dominus Novi Castri, Weiskirch vulgariter nuncupati genannt wird. [So z. B. Chmel Reg. Friderici 946]. 
dächtigen Qnellen geboten wurde. So ist der Inhalt dieser Urkunde ein neues Glied in der Kette der Beweise gegen die Echtheit der besprochenen Diplone.

Weder die Urkunde über Weisskirchen noch irgendwelche andere aus der Kanzlei Albrechts weiss etwas von den verdächtigen Angaben und Verfügungen der Fälschungen. Es gibt jedoch eine Ausnahme. In einer im Original erhaltenen Urkunde Albrechts vom 29. April $1439^{1}$ ) werden dem Kanzler folgende Privilegien bestätigt: die Urkunde vom J. 1422 über die Erhebung in den Freiherrenstand, die Schenkungsurkunde von Bassano, die Bestätigung der Schenkung vom J. 1433 und die beiden Diplome über die Erhebung in den Reichsgrafenstand. Ausserdem wird allgemein von etlichen andern Gnadenbriefen gesprochen. Albrecht confirmirt hier also im zweiten Jahre seiner Regierung von den Schlickschen Urkunden gerade diejenigen ausdrücklich, welche wir als Fülschungen nachgewiesen haben. Und man kann hinzufügen, welche auch dem König als Fälschungen erscheinen mussten. Denn die Herkunft und der Lebenslauf des Kanzlers war ihm bestimmt so gut bekanut, wie einst Sigismund. Es gehört nicht hieher zu erzählen, wie oft Albrecht an dem Hofe seines Schwiegervaters anwesend war, wie eng seine politischen und Familieninteressen mit denjenigen des Kaisers verknüpft waren. Die Erfolgê der Politik Sigismunds in Böhmen und Ungarn, der Verhandiungen, welche zum Theil von Schlick geleitet wurden, waren für Albrecht nicht minder schwerwiegend als für den Kaiser selbst. In der Urkuude über die Schenkung von Weisskirchen wird gesagt, der König hätte sich von den Verdiensten des Kanzlers oft selbst überzeugt: propria nostra contemplati,ne sepenumero curiam dicti domini imperatoris visitando experientiam sumpsimus evidentem, und der Inhalt der Urkunde schliesst es rollends aus, dass Albrecht über das Leben Schlicks nicht genügend unterrichtet gewesen wäre.

Oder: Albrecht hätte den nach zwei Jahren vorgelegten Urkunden über die Erhebung Schlicks in den Grafenstand Glauben geschenkt?

Wäre die Bestätigungsurkunde echt, hätten wir es mit eiuem kaum lösbaren Räthsel zu thun.

Das Original der Bestätigung ist kanzleigemäss und sowohl der Text als auch die Unterfertigung: dominus rex in consilio von der Hand a geschrieben. Die Drkunde wurde ferner auch in das Reichsregister $\mathrm{M}$ auf fol. 57/ eingetragen. Auf den ersten Blick sieht man, dass sie daselbst in eine bei der ersten Beschreibung der Blätter leer-

1) Archiv in Kopidlno II. 10. 
gelassene Lücke zugleich mit einer zweiten Urkunde eingefügt wurde. Man hatte aus irgend einem Grund anderthalb Seiten leer gelassen und die zwei Urkunden füllen den Raum nicht vollständig aus.

Das zweite der eingeschobenen Stücke ist nun ebenfalls eine Urkunde für Schlick. Albrecht bestätigt in derselben die gefälschte Urkunde Sigismunds vom J. 1437 über die adelige Abstammung des Kanzlers und die Ebenbürgikeit seiner Ebe mit der Herzogin von Oels. So finden wir ganz analog wie im Reichsregister L die ganze Gruppe der behandelten Fälschungen in einem Nachtrage vereinigt.

Die Buchung erfolgte von einer anderen Hand als diejenige der vorangehenden und folgenden Stücke ${ }^{1}$ ). Wohl wechseln in den Registerbüchern Sigismunds und Albrechts die Hände, aber bei weitem nicht so oft, wie man nach den Ausführungen Seeligers meinen könnte. Mehrere Schreiber neben einander thätig finden wir im Register E. Im Register F schreibt eine Hand bis auf fol. 20/v, von da bis zum Schlusse eine zweite Hand, mit Ausnahme einer nachgetragenen Urkunde auf fol. 130/p. Dieselbe Hand schreibt das ganze Register G mit Ausnahme einer Urkunde auf $175 / v$ (am Rande nachgetragen) und einer auf fol. 179 (kein Nachtrag), ferner durchwegs das Register $\mathrm{H}$ und in Register $\mathrm{J}$ bis zum fol. 196. Es folgt dann eine neue Hand, welche ausnahmslos alle Eintragungen in den Reichsregistern $\mathrm{K}$ und $\mathrm{L}$ also bis zum Tode Sigismunds besorgte. Derselbe Schreiber fängt nun auch das Register Albrechts zu schreiben an und registrirt bis auf das fol. 13. Die letzten Stücke, die er eingetragen, sind vom September 1438. Sein Nachfolger liess zwei Blätter leer, auf welche später zwei Urkunden eingetragen wurden, beginnt auf fol. 15 mit dem Worten: In Vratislavia 2 die Decembris incepi in hoc registro und schreibt den Band zu Ende. Mit Ausnahne von 4 Urkunden. Zwei sind uns bereits bekannt, es sind die nachgetragenen Stücke für den Kanzler, und zwei von derselben Hand stehen als letzte Stücke am Schlusse des Registers'a). Es sind ebenfalls Urkunden für Kaspar Schlick. Und Urkunden, von denen wenigstens eine recht verdächtig ist.

Im J. 1429 gewährte Sigismund der Stadt Rothenburg die Begünstigıng, duss ihre Stadtsteuer nie verpfändet werden darf. $^{3}$ ). Er scheint darauf vergessen zu haben und gebot ein Jahr später die Steuer an Schlick auszuzahlen ${ }^{4}$ ). Die Stadt protestirte, die Verfügung wurde rückgängig gemacht, die Begünstigung von neuem bestätigt und die

1) Tafel II. 2.

2) Fol. 72 .

s) Altmann 7458 .

4) Daselbst 7927 . 
Rothenburger zahlten die Steuer direct in die kaiserliche Kammer ${ }^{1}$ ). So auch "nach laut ihrer Freiheit" unter Albrecht²). Und nun soll wiederum kurz vor seinem Tode und 7 Jahre nach der Entziehung der Steuer dem Kanzler Sigismund am 16. Oct. 1437 dem letzteren eine Urkunde ertheilt haben, in welcher er sich verpflichtet, ihn und seine Erben für die Steuer schadlos zu halten und dieselbe ihnen aus der Kammer auszuzahlen? Das Original der Urkunde ${ }^{3}$ ) ist von dem an den Fälschungen Schlicks thätigen Schreiber $b$ geschrieben und im Reichsregister L. 14|v als Nachtrag auf dem Rande eingetragen. Albrecht bestätigt angeblich ebenfalls kurz vor dem Tode diese Urkunde ${ }^{4}$ ). Das zweite der am Schlusse registrirten Stücke ist eine Geldverschreibung an den Kanzler und entzieht sich jeder Controle. Die Urkunden sind vom 7. September, es gehen jedoch Stücke bis zum 1. October voran (fol. 71/v). Die letzten zwei Eintragungen erfolgten also entweder in den letzten Tagen oder nach dem Tode Albrechts. Es liegt vielleicht die Vermuthung nahe, dass auch die übrigen zwei nachgetragenen Schlickschen Urkunden, da von derselben Hand, auch in derselben Zeit registrirt wurden. Und die Hand, welche dies besorgte ist die Hand a, eine Hand die sonst nie weder in den Registerbüchern Sigismunds noch in jenem Albrechts vorkommt, jene Hand, welche die Originale der gefälschten Diplome über die Erhebung Schlicks in den Reichsgrafenstand und auch dasjenige der Confirmationsurkunde Albrechts geschrieben hat ${ }^{5}$ ). Das bedarf keines Commentars.

Die Art und Weise, wie der Kanzler die Fälschungen gegen jeden Verdacht zu sichern versucht hat, dürfte aus dem gesagten klar geworden sein. Wir vermögen nun auch den Gegenbeweis zu liefern. In dem einzigen uns erhaltenen Register der böhmischen Kanzlei Sigismunds vom September 1436 bis zum Tode des Kaisers finden wir nicht weniger als sechs später eingefügte Urkunden für Schlick 6 ). Eine derselben wurde auf fol. 151 in eine Lücke eiugeschoben, welche dadurch entstanden ist, dass man von einer Eintragung nur den Anfang

1) Daselbst 7972, 8877, 8956, 9244, 10782, 11451, 12122.

2) RR. M. 17/v, 70/v.

s) Kopidlno X. 2. Altmann 12129 Fälschung?

4) In den Registerbüchern Friedrichs steht stets neben der Eintragung der Quittung für Rothenburg eine Notiz, dass die Steuer an Schlick ausgezahlt wurde. Friedrich bestätigte also thatsächlich die Urkunden. In den Registerbüchern $\mathrm{L}$ und $\mathrm{M}$ ist selbstverständlich ein solcher Vermerk nicht zu finden.

b) Tafel II.

6) Das Register von Altmann mit $\mathrm{L}^{1}$ bezeichnet befindet sich in der Fürst Lobkowitz'schen Bibliothek in Raudnitz. 
schrieb und für den Rest anderthhalb Seiten leer gelassen hat1). Die nachgetragene Urkunde füllt diesen Raum nicht ganz aus. Die übrigen 5 Urkunden stehen als die letzten Stücke am Schlusse des Registers. Also derselbe Befund wie in den Reichsregistern. Der Band ist äusserst sorgfältig in continuo geschrieben, ausser den Schlickschen Urkunden lassen sich keine Nachträge constatiren ${ }^{2}$ ). Bis auf das fol. 70/ schreibt eine Hand, dieselbe, welche gleichzeitig die Eintragungen im Reichsregister besorgt, von fol. $\left.70\right|^{v}$ an bis zum Schlusse des Registers eine zweite. Es ist dies die Hand $b$, diejenige, welche die in die J. 1422 und 1433 datirten Fälschungen Schlicks geschrieben hat. Von dieser Hand sind auch die Nachträge, die sich aber durch eine viel sorgfältigere Niederschrift von den sonstigen Eintragungen scharf abheben ${ }^{3}$ ). Der Schreiber mochte als er diese Stücke registrirte, nicht mehr so viel zu thun gehabt habeu, wie während des Aufenthaltes Sigismunds in Böhmen.

Drei von den nachgetragenen Urkunden enthalten Geldverleihungen ${ }^{4}$, zwei betreffen das Schloss Schöneck im Vogtlande, welches bis jetzt die Herzoge von Sachsen pfandweise von der böhmischen Krone innehatten und dasselbe laut einer der Urkunden ${ }^{5}$ ) in J. 1437 dem Kanzler ebenfalls pfandweise überlassen haben. In der zweiten Urkunde gibt Sigismund seine Zustimmung dazu und verfügt, dass Schlick das Schloss als Erbeigenthum besitzen soll6). Die sechste Urkunde ist nun bestimmt eine Fälschung. In derselben schenkt Sigismund das Gut Lichtenstadt im Elbogner Kreise, welches er einst von dem Kloster zu Tepl gekauft und zugleich mit Elbogen dem Kanzler verpfändet hat, dem letzteren als Erbeigenthum ${ }^{7}$ ).

Die Urkunde ist uns auch im Original erhalten im Wiener Staatsarchiv ${ }^{8}$ ). Das Original ist kanzleigemäss und von der Hand b geschrieben. Daselbst befindet sich eine Urkunde Albrechts über die Schenkung mutatis mutandis wörtlich desselben Inhaltes wie das Diplom

1) Tafel III. 2.

2) Lücken finden wir ausser der genannten nur noch zweimal : auf fol. 142 hatte der Schreiber eine Urkunde für die Einzinger einzutragen begonnen, dann abgebrochen und ein Blatt leer gelassen. Später wurden zu dem Bruchstïcke die Worte gsschrieben: Quere ante immediate. Aehnlich finden wir auf fol. 145 nur die ersten Worte einer Urkunde und dann anderthalb Seiten leer.

3) Tafel III. 4) Altmann 12144, 12154, 12176 . 5) Altmann 12064.

$\left.{ }^{6}\right)$ Altmann 12072. Gegen das Uebereinkommen, welches er vor kurzem mit den böhmischen Ständen getroffen hat, Krongüter nicht zu veräussern? In der Theilungsurkunde zwischen Mathias, Wenzel, Niklas und Sigismund Schlick aus dem J. 1472 wird von der ,Pflegschaft ‘ Schöneck gesprochen (Kopidlno VII. 1).

7) Altmann 12018 .

8) Boh. 1296. 
Sigismunds, dessen keine Erwähnung geschiebt. Es ist ebenfalls von der Hand $b$ geschrieben und der Urkunde Sigismunds in der Ausstattung bis zum Registraturvermerke so gleich, dass man vermuthen könnte, sie seien an einem Tage mit einer Feder geschrieben. Wir besitzen eine Orkunde Albrechts vom 20. Sept. 1438, in welcher er dem Kanzler die Verpfändung von Elbogen bestätigt1). Unter den Gütern, welche zu der Pfandschaft gehören, wird auch ,und sonderlich das gut zu Lichtenstadt" genannt. Schlick und seine Erben sollen diese Güter so lange bebalten, bis ihnen die ganze Pfandsumme ausgezahlt wird. An einen Irrthum ist nicht zu denken, gegen den hätte Schlick gewiss protestirt, folglich existirte die Urkunde noch nicht, oder der Kanzler wagte nicht mit derselben hervorzutreten ${ }^{2}$ ).

Der Inhalt und die Ueberlieferung lassen eine Reihe von Schlickschen Urkunden als Kanzleifälschungen aus der Kanzlei Sigismunds und Albrechts erscheinen. In den älteren bekannt gewordenen Falsificaten dieser Art wurden Diplome vergangener Zeiten hergestellt, der Auftraggeber benützte die im Urkundenschreiben bewanderte Kanzleikraft ohne die iuridischen Beglaubigungsmittel der Kanzlei in Anspruch zu nehmen ${ }^{3}$ ). Anders die Fälschungen Schlicks. Der Kanzler lässt unechte Urkunden seiner Zeit herstellen, welche in der Kanzlei geschrieben, gefertigt, besiegelt und zum Theil anch registrirt wurden. Ein ähnlicher Fall liegt uns bezeichnenderweise ebenfalls aus der Kanzlei Sigismunds vor ${ }^{4}$ ). Im J. 1426 legte Herzog Erich von Lauenburg eine ihm angeblich im J. 1414 über die Belehnung mit Sachsen verliehene Urkunde vor. Sigismund erklärte, die Urkunde sei ohne sein Wissen und Befehl ausgestellt worden. Durch eine Untersuchung wurde festgestellt, dass die Fälschung im J. 1422 auf Befehl des Kanzlers Georg von Passau in der Kanzlei geschrieben, von Priest gefertigt und von Fye registrirt wurde. Obwohl die Schuld der letzteren erwiesen war, behielt man sie in der Kanzlei und das ist beinahe interessauter als die Fälschung selbst.

1) Kopidlno XI. 4.

2) Nach dem Muster der Schenkung von Lichtenstadt fälschten die Schlick (wahrscheinlich die Bräder Kaspars) eine gleichlautende Urkunde über Falkenau (Altmann 11218). Die Schrift der Fälschung ist eine ungeschickte Nachahmung einer Kanzleiband.

3) Vgl. über die ălteren Kanzleifälschungen Bresslau 79.

4) Vgl. Aschbach Sigmund 3. $227 \mathrm{ff}$, Rieger W. SB. 76. $493 \mathrm{ff}$. und Lindner 201 ff. Ueber die Fälschung eines Notars der Reichskanzlei unter Karl IV. vgl. Kaiser. Der collectarius perpetuarum formarum des Johann von Gelnhausen. Strassburg 1898. S. 125. 
Im frühen Mittelalter sind Kanzleifälschungen in diesem eminenten Sinne wohl nicht unmöglich, aber doch unwahrscheinlicher. Der Gang der Beurkundung, die persönliche Antheilnahme des Herrschers an jedem einzelnen Stücke, der Wechsel der Kanzleileitung mit dem Tode des Regenten, erschwerten das Gelingen eines solchen Versuches. Das ändert sich jedoch nach und nach und es ist zweifellos, dass unter Sigismund und seinem Nachfolger in der Geschäftspraxis die Gelegenheit zu Malversationen, wie denjenigen des Georg von Passau, des Priest, des Fye und des Schlick geradezu geboten wurde. Ich verweise dafür auf die Ausführungen Lindners und Seeligers. Dazu kommt eine Reihe anderer Momente.

Es wäre eine höchst dankbare Aufgabe einmal die Wandlungen des gesellschaftlichen und rechtlichen Ansehens der Kaiserurkunde, ich meine nicht ihrer theoretischen Rechtskraft, zu verfolgen. Das Urkundenwesen der Kaiser des früheren Mittelalters beruht auf in den Grundzügen einfachen und relativ wenig differenzirten Rechtszuständen. Nachdem diese Voraussetzung entfallen war, beginnt die ganze Institution zu wanken. Die alten Recht und Gesetz schaffenden Formeln müssen weichen und werden immer mehr durch eine subjective Fassung der einzelnen Diplome ersetzt. Dazu kam der Zerfall des Imperiums. Man gewöhnt sich in der Kaiserurkunde de facto mehr eine persönliche Begünstigung des Kaisers zu achten, eine Begünstigung, welche für Dienste, Parteitheilnahme und vor allem auch für Geld zu haben war. Man fälschte im späterı Mittelalter verhältnismässig viel weniger Kaiserurkunden als früher, man legte keinen Wert auf die Sache.

Mit den neuen Aufgaben verändert sich bekanntlich die Stellung, die Verwaltung und die Organisation der Kanzlei. Aber erst nach und nach wurde sie dem neuen Verwaltungsstaate eingeordnet und so gibt es in ihrer Geschichte eine merkwürdige Debergangszeit, fast möchte man sagen ein Todesringen der alten Institution. Herrscher, denen eine Ordnung des Urkundenwesens am Herzen lag, zogen in die Kanzlei fachmännisch geschulte Kräfte und das sind bei dem immer noch universellen Charakter der Zeit nicht nur Juristen, sondern Leute von allgemein literarischer Bildung. Das führt zu Consequenzen, welche wohl über das Gewollte hinausgehen, welche einzig in der Geschichte der Aemter dastehen dürften: die Kanzlei wird ein Mittelpunkt der literarischen Bestrebungen der Zeit und diese Bestrebungen erstrecken sich nicht nur auf das Privatleben der Beamten. Die letzteren konnten es wagen, das feste Gefüge der Orkundensprache ihren schriftstellerischen Passionen zu opfern wie unter Karl. 
Unter Sigismund und seinen Nachfolgern stand das Niveau der Kanzlei nicht so hoch. Am Hofe Sigismunds lebten viel Leute, welche Schiffbruch gelitten hatten oder ein Glück machen wollten - panis quaestores et auri corrassores. Ein Aufsatz von Herzberg-Fränkel belehrt uns über Zustände, welche im 13. und 14. Jahrhundert am deutschen Hofe in Bezug auf Pflichttreue, Verlässlichkeit und Anstand der Beanten herrschten 1), Zustände, welche später wiederkehren. Das System der Entlohnungen von Fall zu Fall brachte es mit sich, dass man auch da Entlohnungen suchte, wo es keine gab. Das Kanzleipersonal unter Friedrich, es ist zum Theil dasselbe wie unter Sigismund und Albrecht, wird von Enea Silvio als ein Gesindel geschildert, von dem er Ekel empfunden habe, als eine hungrige Meute, welche jede Gelegenheit benützte, wo es etwas zu verdienen gab.

Und Schlick? Der Einfluss, welchen er in den letzten Jahren Sigismunds genossen hat, war nicht in seiner Kanzlerthätigkeit begründet, die letztere war seinem freien Schalten und Walten völlig überlassen. Er betrachtete die Kanzlei stets ein wenig als sein Privatunternehmen. Mehr als seine Vorgänger benützte Schlick die Kanzlei, um sich zu bereichern ${ }^{2}$ ). Man müsse 6000 verlangen $\mathrm{um} 3000 \mathrm{zu}$ bekommen, so hätte er es selbst gethan, räth er dem Alberichs Maletta ${ }^{3}$ ). „Wiesset auch, lieben hern, daz ber Casper der canceler die stede groszlich besweret, die ir confirmacien sollent han ur der canceli" schreibt am 22. Nov. 1433 Walther von Schwarzenberg aus Basel an den Rath von Fraukfurt4). Der Kaiser konnte keinen Einwand erheben, denn er lebte selbst nicht selten für Wucherzinsen von dem Gelde, welches der Kanzler eingetrieben hat.

Aus den Briefen Schlicks und Silvios kann man sich einen Begriff machen von der vollständigen Unbedenklichkeit in der Wahl der Wege, welche zu einem erwünschten Ziele führen sollten. „Ut homines sunt ita utamur. Extrahendum est ex petra mel et oleum ex saxo durissimo" heisst es da einmal 5). Eine Grenze zwischen den Pflichten einer öffentlichen Amtsstellung und der persönlichen Begierde wurde nicht nur nicht gezogen, sondern nicht einmal empfunden, der Einfluss des Kanzlers wurde unbedeuklich als Lock- und Drohmittel ausgenützt ${ }^{6}$ ), und

1) Mitth. d. Instituts 15. $458 \mathrm{ff}$.

2) Es liesse sich eine lange liste zusammenstellen aus Nachrichten über die Geschenke und das erpresste Geld, welches der Kanzler empfangen hat.

3) 1443 Sept. 16. Grätz. Cod. lat. 5311 der Münchner Hofbibl. 211/v.

4) RA. XI. 210.

5) Brief des Silvio an Schlick. Voigt 79.

6) Vgl. den Brief des Silvio an Ludovico d'Allemand. Voigt 49. 
in Bezug auf offen zur Schau getragene Verlogenheit, wird da geleistet wie nicht so bald in der Renaissanceliteratur. In der Angelegenheit des Bisthums Freising - um ein Beispiel zu nennen - welches der Kanzler durch seinen Bruder besetzt zu haben wünschte, ward der König und der Papst Jahre hindurch betrogen, dem König sagte man der Papst, dem Papst schrieb man der König wünsche es, dass der Bruder des Kanzlers Bischof von Freising werde ${ }^{1}$ ). Endlich ist die Sache aufgekommen und Friedrich schrieb an den Papst, er möge Heinrich Schlick ein perpetuum silentium anferlegen ${ }^{2}$ ). Einige Jahre später publicirte dann Silvio seine auf die Angelegenheit sich beziehende Correspondenz, in der er selbst als ein Theilnehmer des Betruges erscheint. Burckhardt sagt. von Silvio, er wäre stets in allen Dingen so aufgegangen, dass ein sittlicher Zwiespalt ganz ausgesehlossen war. Vom Schlick gilt nur der zweite Theil des Satzes. Der Kanzler war keine alltägliche Erscheinung, er besass Kraft und Talent, aber es haftet allen seinen Bestrebungen eiwas Schmutz an und auch etwas Kleinbürgerliches, es sind die Bestrebungen des Tuchhändlersohnes aus der Judengasse in Eger, welcher zu einer vollen Schüssel gesetzt wurde.

Es gibt noch mehrere Urkunden ausser den besprochenen, welche Schlick von Sigismund erhalten haben soll und welche Verdacht erregen. Aus den letzten Monaten der Regierung des Kaisers stammt über ein Drittel aller Urkunden, welche der Kanzler durch alle die Jahre von Sigismund bekommen hat. Es sind darunter geradezu abenteuerliche Verfügungen, an deren Vollziehung nicht zu denken war, die auch nie in Rechtskraft getreten $\operatorname{sind}^{3}$ ). Es ist mir und wahrscheinlich auch überhaupt nicht möglich zu entscheiden, welche von diesen Urkunden echt und welche gefälscht sind, man dürfte bei den

1) Vgl. Voigt, Enea Silvio I. $308 \mathrm{ff}$. und die zahlreichen Briefe des Silvio und Schlick in dieser Angelegenheit.

2) Cod, lat. der Münchner Hofbibliothek 11725 fol. $121 / \mathrm{v}$ ff.

3) So verleiht er ihm am 24. August 1437 das viel umstrittene Erbe des Grafen Friedrich von Toggenburg (Altınann 12059 Fälschung?), belehnt den Kanzler am 6. Nov. 1437 mit dem ebenfalls strittigen Fürstenthum zu Wenden (Altmann 12168). Als Heiratsgut schenkten der Kaiser und die Kaiserin Schlick und seiner Gemahlin 700 ungar. Gulden. Ueber die Verschreibung besitzen wir zwei verschiedene Urkunden rom gleichen Datum 6. April, eine im Original (Kopidlno II. 1), die zweite in Reichsregister L. 47 (bei Altmann beide als eine Orkunde unter der Nr. 11752). In der zweiten Urkunde wird zu der Geldverleihung noch das Versprechen zugefügt, dem Kanzler ein Schloss in Ungarn zu schenken. Falls der Kaiser oder seine Erben dieses Versprechen nicht erfüllen sollten, wird der Kanzler ermächtigt sich mit Gewalt zu entschädigen. 
meisten aus naheliegenden Ursachen über allgemeine Verdachtsgründe nicht hinauskommen. Es liegt auch nicht viel daran.

In den letzten Tagen Sigismunds oder bald nach dessen Tode nochte der Kanzler den Gedanken gefasst haben durch eine Reihe von Fälschungen sich und seiven Erben einen grösseren Besitz und eive höhere und besser fundirte gesellschaftliche und rechtliche Stellung zu verschaffen. Es bekommt nun eine neue Bedeutung ein inerkwürdiges Document, welches sich Schlick zwei Tage uach dem Tode des Kaisers ausstellen liess. Es ist dies eine Urkunde Herzog Albrechts und des Pfalzgrafen Christof, in welcher dem Kanzler bestätigt wird, dass alle ihm anvertrauten Siegel und Stempel an dem Tage des Datums der Urkunde in der St. Nikolauskirche zu Znaim nach der Messe auf dem Altare durch einen Goldschmied zerbrochen wurden ${ }^{1}$ ). Wir haben kein zweites Beispiel für diesen feierlichen Vorgang, kein zweites Beispiel eines Attestes, der über die Siegelbrechung ausgestellt worden wäre. Es ist auch nicht zu ersehen, warum gerade Schlick, der sonst nicht im mindesten rigoros war, auf eine solche Sicherstellung Wert gelegt hätte, wenn eben nicht ein besonder Grund vorhanden gewesen wäre.

Die Urkunde ist kein terminus ad quem für die Entstehungszeit der Fälschungen. Der Kanzler konnte sich eine Reihe rou Membranen hergestellt haben, wie man sie auch sonst in der Kanzlei besessen hat ${ }^{2}$ ). Jedenfalls sind die Falsa noch unter der Regierung Albrechts entstanden, denn nach seinem Tode scheidet Schlick auf zwei Jahre aus der Kanzlei. Und da die gefälschten Urkunden Sigismunds in das Register noch von jener Hand nachgetragen wurden, welche unter Albrecht die Buchung nur bis September 1438 besorgt und dann verschwindet, könnte man vielleicht vermuthen, dass die Diplome vor dem letzteren Zeitpunkte entstanden sind.

Unter Albrecht scheint Schlick sehr wenig mit der Verwaltung der Kanzlei zu thun gehabt zu haben. Er unterfertigt nur selten, seine Hauptaufgabe lag in der politischen Thätigkeit. Wahrscheiulich wollte er den neuen Schreiber, welcher seit dem September 1438 die Registrirung besorgte und dem der Inhalt der gefälschten Bestätigungsurkunden Albrechts auffallen musste, nicht ins Vertrauen ziehen und liess sie von jenem Ingrossisten eintragen, welcher von der Sache wusste, welcher einen Theil der falschen Diplome Sigismunds und die Bestätigungsurkunden geschrieben hat.

') Orig. in Kopidlno II. 2 gedruckt bei Lünig RA. Spec. saec. II. 1187.

2) Vgl. Lindner $181 \mathrm{ff}$. 
Nach dem Tode Albrechts versuchte bekanntlich Erzbischof Dietrich von Mainz seine Rechte geltend zu machen und ernaınte Jacob von Trier zum Kanzler. Friedrich fügte sich und der Bischof verwaltete zwei Jahre das Amt'1). Aus Gründen, denen noch nachzugehen wäre, wird jedoch im Sommer 1442 Schlick wieder zum Hofe berufen und mit der Leitung der Kanzlei betraut. Bald nach seiner Ankunft legte er dem König die Fälschungen vor: das Freiherrendiplom vom J. 1422, die Schenkungsurkunde von Bassano, die Privilegienbestätigung vom J. 1433, die lateinische Urkunde über die Erhebung in den Reichsgrafenstand, wie auch die Bestätigungsurkunde Albrechts ${ }^{2}$ ). Friedrich war jung, über die Verhältnisse am Hofe Sigismınds kaum näher unterrichtet, vertraute auch später blind dem Kanzler. Das Gefolge Sigismunds in den letzten Monaten seines Lebens und vor allem nach der Flucht aus Prag war nicht besonders zahlreich. Albrecht war ein Zeuge der letzten Verfügungen des Kaisers, aber seinem Nachfolger konnte wohl Schlick über dieselben Beliebiges erzählen. Das sind ja Dinge, über die es keine Aufzeichnungen gibt. Friedrich schenkte den formell unantastharen Urkunden Glauben, am 8. August erfolgte die Bestätigung.

Erst jetzt versuchte Schlick auch eine Zustimmung der Kurfürsten zu der Erhebung in den Reichsgrafenstand zu erlangen ${ }^{3}$ ). Erst jetzt hat sich die Nachricht von seinem neuen Namen verbreitet4). Der Umstand, dass Schlick auch fernerhin den Titel eines Grafen von Bassano nicht führt, ist nicht nur nicht auffallend, sondern dürfte im Gegentheil besagen, dass sich der Kanzler auch jetzt noch nicht sicher fühlte; die Sache konnte auch jetzt noch Zweifel und Widerspruch erregen, hauptsächlich in Venedig. Er war ihm auch weniger um das Prädikat zu thun.

Im J. 1443 trat Silvio in die Reichskanzlei ein und bald stand Schlick vollständig unter seinem Einflusse. Der junge Italien er war der präpotentere Geist und nützte den Kanzler für seine Zwecke aus. Unter seiner Leitung versuchte Schlick eine selbständige Politik zu treiben, mit welcher der König nicht immer eiuverstanden war. Im J. 1448 ist er in Ungnade gefallen, wir wissen nicht warum. Ein Jahr später ist er gestorben. Sein Bruder Mathäus reiste nach Wien, um die Verlassenschaft des Kanzlers zu übernehmen. Er schreibt aus Wien einen

1) Vgl. Seeliger, Erzkanzler $62 \mathrm{ff}$.

2) Reichsregister O. 167, 169. Chmel Reg. Friderici 946, 947.

s) Willebrief des Erzbischof Dietrich zu Cöln vom 24. Oct. 1443. Kopidlno IV. 14. Lünig RA. Sp. saec. II. 1192.

4) Vgl. Silvius Hist. Boh. §1, ferner Chmel Reg. Fr. 2011. 
interessanten Brief an Clrich von Rosenberg. Er bittet ihn keinen Glauben dem Gerüchte zu schenken, dass nach seines Bruders Tode „mer dann hundert versigelter karten gefunden sollten sein "1). Kann man annehmen, dass ein solcbes Gerücht aus der Luft gegriffen wurde?

Jedenf:alls bezeugt es, dass von einer Fälscherthätigkeit Schlicks, jener Art, wie sie sich aus den Urkunden ergeben hat, bereits von den Zeitgenossen gesprochen wurde.

Im J. 1498 versuchten die Schlick die in deı Fälschungen enthalteneu Rechte auf Bassano geltend zu machen. Kaspar II. Schlick schrieb deshalb nach Venedig. Er bekam keine Antwort. Er bat nun Peter von Rosenberg sich der Sache anzunehmen. Derselbe schrieb dem kaiserlichen Orator in Venedig und ersuchte ihn zu veranlassen, dass Kaspar Schlick irgendwelche Antwort bekomme ${ }^{2}$ ).

Das Prädikat der Grafen von Bassano führen die Schlick erst im 16. Jahrhundert, erst in dritter Generation.

\section{B e i l a g e n.}

I.

K. Sigismund erhebt Kaspar Schlick und seine Erben in den Freiherrenstand und erweitert ihr Wappen durch dasjenige der Grafen von Collalto.

\section{Juli 16 Nürnberg.}

In nomine sancte et individue trinitatis feliciter amen. Sigismundus dei gracia Romanorum rex semper augustus ac Hungarie, Boemie; Dalmacie, Croacie etc. rex spectabili et nobili Casparo Slik secretario ${ }^{3}$ ) nostro et sacri imperii fideli dilecto graciam regiam et omne bonum. Altitudo omnipotentis dei regnantis in throno, sicut universalis ierarchie tam in celestibus quam terrenis congruum disponit ordinem, sic condicionem et statum componit hominum, ut et alii aliis presideant et recto moderamine inferiores superioribus obsecundent, nec frustra divina providencia limitem ponit singulis; humana etenim natura ad malum prona, nisi duris stringeretur loris, nullis posset retineri piaculis, quin per campos malicie insolentibus maliciis vagarentur. Sic et regie dignitatis celsitudo romane previis formata presidiis et exemplis, quantum humane fragilitati permittitur, hiis sue magnificencie conatur prebere graciam super alios excellencie pocioris, quos tam virtutum meritis, quam probate fidei experiencia ceteris per effectum operis noverit prelucere nec inmerito hos ad alta provehit et ad hoc dirigit studium, ut et alii similibus tracti beneficiis erga dominos suos crescant in fide, ipsis sedula prestent fidelitatis obsequia et in singulis subieccionis officiis se conforment. Sane quamvis ex multorum generosorum et magnificorum virorum comitum et baronum et

1) Archiv in Wittingau: Familie Schlick. Orig. vom 20. Nov. 1449 Wien.

2) Concept im Wittingauer Archive vom 9. Juli 1498 Prag Familie Schlick.

s) Auf Rasur von derselben Hand. 
signanter magnifici Guilielmini comitis Prate consiliatii nostri fidelis dilecti clara informacione simus sufficienter edocti, quod a maternis sedibus ex illa ingenua et nobili comitum de Colalto et Sancti Salvatoris domo, qui retroactis temporibus marchiam Trevisanam et alia gloriosa tenuerunt dominia et adhuc plura retinent, intermisse originem traxeris, cum generosa Constancia mater tua magnifici Rolandi comitis Colalti et Sancti Salvatoris legitima et unica fuerit heres sua et superstes, quam ex nobili uxore sua de domo comitum de Camino procreavit, ex paternis vero sedibus a nobile (sic) et famoso Henrico Slik ex militari genere procreato et per nos ad uberioris nobilitatis apices evecto processeris, suscepimus tamen devotissimam supplicacionem tuam sic continentem, quatenus te, qui in singulis maternis hereditatibus atque bonis verus sis heres et successor et patre ex militari ordine procreatus, dignaremus habilitare et erigere, teque in baronem et procerem preficere ad capienda et tenenda bona tibi de iure ex successione materna conpetencia et debenda. Nos igitur tuis humilibus permoti precibus pensantes firmam constanciam et intemeratam laboris diuturnitatem, fidelia quoque servicia, que nobis a teneris annis sequendo nos per Arragonie, Francie, Anglie aliaque plurima regna gravibus laboribus et fatigis sedulus impendisti, cotidie exhibes in latere nostro et capitaneorum nostrorum contra hereticos Boemie et perfidos Turcos, adversus quos iam cum persone et rerum tuarum discrimine plerisque processisti vicibus, nosque te in variis et arduis legacionibus ad diversos reges et principes continue ut hunc de quo tamquam secretario nostro ${ }^{1}$ ) singulari quadam fide confilimus, dirigamus, et in antea quidem tanto ficlelius te erga nos et imperium exhibere poteris et debebis, quanto te ampliori perventum conspicis munere graciarum, idcireo non per errorem aut inprovide sed animo deliberato, sano principum, comitum, baronum et aliorum fidelium nostrorum accedente consilio te Caspar prefatum, quem ex parte predicte matris tue et proavorum suorum ingenuorum comitum magnifici generis clara nobilitas reddit insignem, et heredes tuos legitimos imperpetuum de imperiiali plenitudine potestatis hodie in nomine domini salvatoris, a quo omnis honor dependet, in liberum procerem et baronem sacri imperii creamus, erigimus, honoramus, libertamus, exaltamus et ex certa nostra sciencia generosius sublimamus ac habiles facimus, baronias quaslibet immo et bona comitatum et quevis bona nobilium, baronum habendi et possidendi, dum tamen talia empcionis contractu, donacione, devolucione seu quovis alio titulo ad te aut beredes tuos contingerit pervenire et signanter bona, successiones et devoluciones tibi de materna successione tua debencia et debentes, in quibuscunque consistant et qualitercunque nuncupentur, que et tibi et heredibus tuis conferimus tenore presencium et donamus non obstante, quod avunculi tui comites de Colalto moderni dicte matri tue Constancie vinculis et captivitati mancipate universas litteras, munimenta et probaciones nullo iure previo, prout a predictis comitibus et baronibus clarissima informacione percepimus, durius abegerunt, que iure tua, sic ablata tibi Caspar et heredibus tuis reddimus et restituimus per presentes decernentes et cesareo statuentes edicto, quod tu et heredes tui predicti nulli penitus hominum ad provocacionem duelli seu alterius cuiuscumque

t) Auf Rasur ron derselben Hand. 
cause criminalis seu civilis cuiuscumque eciam condicionis extiterint, nisi baronie insigniis fulcito et in nubilitatis gradu constituto teneamini respondere neque sentencias aliquas interlocutorias seu diffinitivas aut testimonium pro antedictis causis pati seu subire racione quacumque, nisi fuerit nobilitate ingenuus, ut prefertur. Mandumus igitur universis et singulis principibus, comitibus, baronibus, militibus, clientibus et generaliter toti universitati sacri romani imperii et aliorum regnorum nostrorum, ad quos presentes deducentur, sub pena imperialis indignacionis et sub aliis penis, quas nostra aut successorum nostrorum Romanorum imperatorum et regum deliberacio in contemptores quoslibet inflixerit iusta qualitatem contemptus racione previa promulgandas, quatenus te et beredes tuos barones revereantur, intitulent et honorent, vobisque ad bona et successionem vestram maternam consequendam contra dictos comites de Colalto avuculos vestros assistant consiliis et auxiliis opportunis. Ot autem inter te, dictos heredes tuos et alios de domo vestra quoad nobilitatis gradum aliqualis habeatur discrecio, tibi et supradictis heredibus tuis tenore presencium indulgemus et elargimur, ut in armorum vestrorum paternorum in signum uberioris ingenuitatis clipeolum parvum maternum nigro colore quadripartitum et albo gestare et deferre valeatis non obstantibus in premissis clausulis et graciis singulis quibuscumque legibus, statutis, consuetudinibus, iuribus seu privilegiis in contrarium editis, quibus omnibus, si et in quantum presenti nostre libertacioni obviare censentur, auctoritate imperiali penitus derogamus, supplentes omnem defectum, si quis quomodo libet conpertus fuerit in premissis. Testes huius rei sunt illustris Albertus dux Saxonie sacri imperii archimarescallus et elector, venerabilis Georgius episcopus Pataviensis et administrator ecclesie Strigoniesis, cancellarius et magnificus Guilelminus comes Prate et alii quam plures fide digni. Presencium sub nostri regalis sigilli appensione testimonio litterarum datum Nuremberge, anno domini 1422, 16 die mensis Julii, anno Hungarie 36, Romanorum 12, Boemie vero 3.

Ad mandatum domini regis Michael prepositus Boleslaviensis.

Orig. auf Perg. Archiv in Kopidlno III. 2. Majestätssiegel an schwarzgelben Schnüren, Heffner Tafel XIV. 98.

$A$ tergo Regest von einer Hand des 18. Jhd.

II.

\section{K. Sigismund schenkt Kaspar Schlick und seinen Erben die Herr- schaft Bassano.}

\section{August 21 Nürnberg.}

In nomine sancte et individue trinitatis feliciter amen. Sigismundus dei gracia Romanorum rex semper augustus ac Hungarie, Bohemie, Dalmacie, Croacie etc. rex. Ad perpetuam rei memoriam. Notum facimus tenore presencium universis. Etsi regalis dignitatis clemencia universorum fidelium, quos imperii sacri latitudo complectitur, felicibus profectibus, gratis, commodis et speratis augmentis favorabiliter dignatur intendere, ad illorum tamen honores, profectus et commoda diligenciori studio inclinari consuevit, quorum fides intemerata, eximia merita, prompteque devo- 
tionis integritas continuatis studiis ceteros antecedunt. Sane considerantes attencius et in animo sedule revolventes solide fidei firmam constanciam ac multiplicia devocionis et fidelitatis insignia, quibus regiam maiestatem nostram nobilis et generosus Caspar Sligk capitaneus terre Egrensis, protonotarius, secretarius et fidelis noster sincere dilectus studuit dignis quidem studiis venerari, illum quoque fervidum amorem sue mentis, quo ad nostros et imperii sacri promovendos honores indefessis quidem laboribus se exhibuit et quod graciarum dator altissimus personam suam industrie et prudencie munere, providencie dono, discrecionis virtute ac generis nobilitate, cum ex ingenua comitum Tervisii et Colalti (familia) originem traxerit ac aliarum graciarum et virtutum titulis multipliciter decoravit, quodque a iuventutis sue primordiis usque ad presentem diem nostris serviciis ita sollerter inhesit, officisque laudabiliter satisfecit nostro lateri non parcendo corpori neque rebus continue assistendo, quod sibi nostram regiam munificenciam atque graciam quodam debito vendicavit; volentes prefato Gaspari pro meritis suis primicias clemencie nostre ostendere et ipsum ad uberiora obsequia animare, idcirco animo deliberato et motu proprio sano principum, magnatum, comitum, baronum et nobilium nostrorum accedente consilio et de certa nostra sciencia eidem Gaspari et heredibus ac successoribus suis legitimis castrum Bassani et civitatem ibidem eum universis et singulis eorum honoribus, dignitatibus, castellis, areis, villis, forteliciis, theloneis, tributis, hominibus, bonis, iuribus, actionibus, iudiciis, iurisdiccionibus, redditibus, proventibus, terrenis, territoriis, regalibus, districtibus, utilitatibus, emolimentis, montibus, collibus, aquis, molendinis, campis, vineis, stratis, venacionibus ac aliis iuribus et pertinenciis universis, quocunque vocabulo nominentur nil penitus dempto, cum mero et mixto imperio et gladii potestate, quomodocunque prefatum castrum et districtus ad nos et imperium sacrum spectent, dedimus, contulimus et donavimus, damus, conferimus et de plenitudine romane regie potestatis vigore presencium graciosius et donamus, ipsumque Gaspar, heredes et successores suos de eisdem tenendis, uti fruendis et hereditarie possidendis clemencius investimus, transferentes in eos universa iura, privilegia, aracias, libertates et exemptiones ac utile dominium, que et quas sacrum imperium aut eiusdem imperii vicarii generales in illo castro et dominio hactenus habuerunt et obtinuerunt, dantesque eisdem Gaspari, heredibus et successoribus suis plenam potestatem ac libertatem prefatum castrum et dominium transmutandi, impignorandi in toto vel in parte, vendendi, alienandi et agendi in omnibus et per omnia, uti eis visum fuerit et opportunum, eximentesque eos ob omni dicione quorumcunque principum, comitum, nobilium, eivitatum ac comitatum quarumcunque, plenam eis et omnimodam libertatem concedentes, ita ut ipsi perpetuis temporibus ad nullum penitus nisi ad nos et successores nostros ac sacrum imperium immediatum respectum habeant, illisque pareant, non obstantibus in premissis onnibus quibuscumque legibus imperialibus, seu municipalibus, communibus seu privatis, statutis, consuetudinibus, decretis, ordinamentis, usanciis et provisionibus quibuscumque editis vel edendis, eciam si tales vel talia forent, de quibus expressam de verbo ad verbum necesse esset ${ }^{1}$ )

1) Im Register steht esse. 
fieri mencionem, quibus omnibus si et in quantum presenti nostre donacioni et gracie seu aliquibus in ea contentis quovis modo directe vel indirecte contrariari possent, ex certa sciencia et de romane regie potestatis plenitudine derogamus et esse decernimus derogatum, supplentes eadem auctoritate omnem defectum, si quis compertus foret, quomodolibet in premissis. Nulli ergo omnino hominum liceat hane nostre donacionis, collacionis, exempcionis, et gracie paginam infringere ant ei quovis ausu temerario contraire. Si quis autem hoc attemptare presumpserit, cuiuscunque condicionis aut dignitatis existat, nostram et imperii sacri indignacionem gravissimam et banum atque omnia gravamina imperialis censure et penam 1000 marcarum auri puri tociens, quociens contrafactum fuerit, se noverit irremissibiliter incursurum, quarum medietatem imperiali erario, residuam vero partem prefato Gaspari heredibus et successoribus suis decernimus applicari, dantes eis plenariam potestatem huius modi transgressores homines et bona eorum pro huiusmodi pena, quam fortassis incurrerent, arrestandi, capiendi et tam diu tenendi, quousque imperio sacro et ipsis pro huiusmodi pena, dampnis et interesse fuerit plenarie satisfactum, mandantes auctoritate regia universis et singulis principibus, comitibus, nobilibus et communitatibus, ceterisque nostris et imperii sacri subditis et fidelibus firmiter et districte, quatenus prefatis Gaspari, heredibus, successoribus et factoribus eorum ad importacionem huiusmodi pene prestent auxilium, consilium et favorem nec aliter faciant, prout indignacionem nostram et imperii voluerint arcius evitare. Presencium sub nostre regalis maiestatis sigilli appensione testimonio literarum. Datum Nuremberge, anno domini 1431, die 21 mensis Augusti regnorum nostrorum anno Hungarie et. 45, Romanorum 21 , Bohemie vero undecimo.

Reichsregister $0.16 \%$.

III.

K. Sigismund bestätigt seinem Kanzler Kaspar Schlick alle Privilegien, von denen die Schenkungsurkunde ïber Bassano namentlich angeführt wird.

\section{Mai 31 Rom.}

In nomine sancte et individue trinitatis feliciter amen. Sigismundus 1 ) etc. Ad perpetuam rei memoriam notum facimus tenore presencium universis. Si quorumcunque fidelium nostrorum honores et commoda quadam innata clemencia libenter promovemus, quanto magis nostram imperialem maiestatem condecet hos manutenere et corroborare in hiis, que a singulari nostra munificencia perceperunt, qui omnia vite sue curricula in nostris imperialibus serviciis consumpserunt. Dignum enim et congruum arbitramur, ut illi precipue partem nostre gracie et beneficiorum ingencium sorciantur, consolacionisque reficiantur antidoto, qui curarum et onerum nostrorum semper fuerunt participes et in adversis nostre maiestati inmobiles astiterunt. Sane hodie, dum altissimi clemencia condonante in eccle-

1) Divina favente clemencia Romanorum imperator semper Augustus ac Hungarie, Boemie, Dalmacie, Croacie etc. rex. im Rejchsregister 0. 
sia sancti Petri huius urbis Romane imperialibus infulis coronaremur, accessit ad nostre maiestatis presenciam magnificus Gaspar Sligk miles, imperialis noster cancellarius fidelis et sincere dilectus, nobisque humiliter supplicavit, quotenus sibi et heredibus suis ac successoribus suis universa et singula iura, libertates, gracias, donaciones, privilegia et concessiones, que et quas a nobis et sacró romano imperio obtinuerunt, super quibuscunque rebus existant et maxime donacionem et concessionem eis de castro et dominio Bassani cum pertinenciis suis dum adhuc romano regio nomine fungeremur factam approbare, innovare et auctoritate cesarea confirmare ${ }^{1}$ ) graciosius dignaremur. Nos itaque considerantes peticionem huiusmodi fore consonam racioni, attendentes eciam servicia ipsius cancellarii nostri maiestati, nostro ${ }^{2}$ ) imperio et regnis nostris a teneris suis annis fideliter impensa, potissime studia et labores, quos inter sanctissimum dominum nostrum papam Eugenium et nostram maiestatem non parcendo corpori neque rebus extendit, ex quibus utrinque laus deo, concupita unanimitas pro bono rei publice christiane ${ }^{3}$ ) est subsecuta, idcirco non per errorem aut inprovide, sed animo deliberato, sano principum, nobilium et fidelium sacri imperii accedente consilio et de certa nostra sciencia prefato Gaspari cancellario nostro, heredibus et successoribus suis universa et singula iura, libertates, gracias, donaciones, literas, privilegia et concessiones, que et quas a nobis et sacro roman $0^{4}$ ) imperio obtinuerunt, super quibuscunque rebus consistant et maxime donacionem de castro et dominio Bassani cum pertinenciis suis eis pridem per nos factam approbavimus, innovavimus et confirmavimus, approbamus, innovamus et tenore presencium auctoritate cesarea et de plenitudine potestatis graciosius ${ }^{5}$ ) confirmamus, volentes et auctoritate cesarea statuentes, ut perpetuis temporibus inviolabilem obtineant roboris firmitatem, illaque et illas firmissime roboris esse decernimus, ac si tenores omnium et singulorum et maxime prefate donacionis de Bassano huic nostre pagine de verbo ad verbum forent inserte, quodque prefatus Gaspar, heredes et successores sui huiusmodi graciis, libertatibus et donacionibus utantur et gaudeant, impedimentis cessantibus quorumcunque, supplentes omnem defectum, si quis comperi posset quomodo libet in premissis. Nulli ergo omnino hominum liceat hane nostre confirmacionis, innovacionis, donacionis et gracie paginam infringere, aut ei quovis ausu temerario contraire. Si quis autem hoc attemptare presumpserit ultra nostram et imperii sacri indignacionem gravissimam; omnes penas in litteris nostris prius expressas se noverit irremissibiliter incursuros. Presencium ${ }^{6}$ ) etc. Maiestas. Datum Rome apud sanctum Petrum ${ }^{7}$ ), anno domini etc. $33^{8}$ ) in festo penthecostes, ultima die mensis ${ }^{9}$ ) Maii, quo in romanum imperatorem

1) Im RR. K. steht confirmaremur.

2) Im RR. O. nostre.

3) Im RR. K. christiano.

4) Fehlt im RR. $U$.

5) Fehlt im RR. K.

6) Sub nostre imperialis maiestatis sigillo testimonio literarum im RR. 0 .

7) a. s. P. feblt im RR. 0 .

8) Im RR O. 1434 .

9) Fehlt im RR. K. 
sumus solempniter coronati, regnorum nostrorum anno Hungarie etc. 47, Romanorum 24, Bohemie 14, imperii vero primo.

Reichsregister K. 232/v und Reichsregister $0.16 \%$.

\section{IV.}

K. Sigismund beurkundet, dass er an seinem Krönungstage Kaspar, Mathias und Wilhelm Schlick auf der Tiberbrücke in Rom zu Rittern geschlagen und denselben ihr Wappen erweitert hat.

\section{Juli 13 Rom.}

Wir Sigmund von gotes gnaden romischer keiser zu allen zeiten merer des reichs und zu Hungern, zu Behem, Dalmacien, Croacien etc. kunig bekennen und tun kunt offenbar mit disem brieve allen den, die in sehen oder horen lesen. Wie wol wir von angeborner keiserlicher gutikeit alczit geneigt sein aller unserer undertanen und getreuen nucz und fromen furczuwenden, idoch so sei wir mer und mer pflichtig und sunderlich gewegen und willig der ere, wirdikeit und ufnemen zu betrachten, die wir von jugent of in unsern diensten willig und mit steter treue unverdrossen befunden haben und die sich tag und nacht so empsiclich und dienstlich gen uns bewiesen, das si uns zu irer furdrung mit billicher pflicht rechtlich verbinden. Wan wir nu angesehen und gnediclich betrachtet haben solich veste und stete true und ouch willige und fleissige dienst, die uns der edel Caspar Slick, ritter, unser und des reichs und ouch der cron zu Behein canczler, pfleger zu Eger und burggraff zum Elbogen unser besunder, heimlicher und lieber getruer lange jare an unserm hofe wesend gar trefflich und nuczperlich getan und sich ouch also bewiset hat, daz er durch unser gnad und sein verdienen und redlikeit von tag zu tag je hoher und von einem ampt zu dem andern gestigen ist, bisz uff die zeit, daz wir nach unserer keiserlichen cron gen Rom czogen, daselbs wir sein vor allen andern unsern reten gen unserm heiligen vater babst Eugenio, gen den von Meilian, gen Venedigern, Florenczern und andern herrn und gemeinden in welischen lannden also gebrauchten, das er uns gros nucz und fromen zubrachte und unsers wolfarens eine grosse ursach was, umb der und anderer trefflichen dienst willen, die er uns dann in deutschen landen und durch die kunigrich von Hiıpanien, Franckreich, Engelland, Ungern, Behem, Polan, Littan, Reussen und ouch in Preussen getan hette und ouch daz er in ettwemaniger grossen herferten und gescheften gen den Turken, in der Walachei, Syrffei und in deutschen landen, auch gen den Behem costlich mit uns geczogen ist, als einen verdienten man mit unsere eigen hand nach emphahung unser keiserlichen cron an dem heiligen pfingstag nechst vergangen uff der Tiberbruck under allen andern, der ein grosse menig gegenwertig was, zu dem ersten ritter slugen und zu unserm ebersten canczlel wirdiclich erhuben und machten und in noch gnediclicher zu handeln vor uns haben und derworten, daz solicher seiner dienste ein warczeichen an sein erben und gancz geschlechte kome, damit man ir dienste in kunffitigen zeiten erkenne. Dorumb mit wolbedachtem mute, gutem rate unserer fursten, graven, herrn und rete und mit rechter wissen von romischer keiserlicher machtvolkomenheit, so haben wir dem egenanten Casparn und den strengen rittern Mathesen und Wilhelm den 
Slicken, die wir ouch uff denselben tag mit unser eigen hand zu Rome ritter slugen, durch irer dienste willen, die si uns in welischen lannden, als lang wir dorinne waren ouch in andern manigen landen in unsern anligenden, notdorfften mit reisen, herfarten und andern ritterlichen geschefften costlich und czerlich teten und sunderiich ouch do wir unserm heiligen vatter dem babst, der von der heiligen kirchen feinden gedrungen wart, hilff sandten in Campaniam, dabi wir dann dem egenannten Mathesen sunderlich befelhnuss taten, dorinne er sich so biderbklich beweiste, das wir in aber mit sunderlichen neuen gnaden geruchten furczusehen. Und wir haben also den egenanten Casparn, Mathesen und Wilhelm und allen iren vettern und irem ganczen geslechte die do Slik genennet sein, iren elichen erben und nachkommen zu bessrung irer kieinat und wapen erlaubt und gegunnet: als si vormals ire wapen von iren eldern und vorfordern mit unsere besserung und verneuung gefuret haben, als dann das wol kuntlich ist, das si nu furbas zu ewigen zeiten zu irem alten helm der flugel, die si mit gulden oder goltfarben leubern besprengen mogen, ouch in der cron uff dem helm einen halben lewen gecronet gulden oder goltfarbe mit uszgestreckten kloen furen und der an allen enden zu schimpff und $\mathrm{zu}$ ernste gebrauchen sollen von ailer menniclich ungehindert. Und wir bestetigen ouch dem egenanten Caspar und allen Slicken, verneuen und confirmirn in ouch von der egenanten keiserlichen macht volkomenheit alle und igliche ire briefe uber ire freiheit, adel, erböhung, gab, pfantschaft oder woruber oder von wem si die suszt haben, nichtz uszgenomen und meinen und wollen, daz die ewiclich unverrücket und in allen iren artickeln und stücken stete gehalden und die egenanten Slik alle und ir iglicher der gebraucheu sollen und mogen. Und wir gebieten dorumb allen fursten geistlichen und werntlichen, grafen, freien, herrn, rittern, knechten und allen des reichs und aller unserer kunigrich undertanen und getruen ernstlich und vesticlich mit diesem brieff, daz si die egenanten Slicken gemeinlich und sunderlich an diesen und allen iren gnaden und freiheiten nit hindern, sunder si der gebrauchen lassen und si dabei hanthaben und schüczen, als lieb einem jglichen sei, unser und unserer nachkomen swere ungnade $z u$ vermeiden und bei verliesung hundert marck lotiges goldes, die ein iglicher, der dawider tut, als offt das geschicht, verfallen sein sol, halb in die keiserlich und kuniglich cammer und halb den egenanten Sliken unleszlich zu beczalen. Mit urkunt disz briefs versigelt mit unserem keiserlichen maiestätinsigel, geben zu Rome nach Crists geburt 1433, an sant Margrethen tag, unsere riche, des ungrischen etc. im 47, des romischen in 23 , des behemischen im 13 und des keisertumbs im 1 jaren.

\section{Ad mandatum domini imperatoris}

Petrus Kalde prepositus Northusensis.

Orig. auf Perg. Kopidlno IV. 4. Majestätssiegel an schwarzgelber Schnur, Heffner Taf. XIII. 96 und 9\%. A tergo der Vermerk O IV. von einer Hand des 15. oder 16. Jhd., das Datum und ein ausführliches Regest von Händen des 18. Jhd. Kein Registraturvermerk. 
V.

K. Sigismund verspricht seinem Kanzler Kaspar Schlick, die ihm geschenkte Herrschaft Bassano nicht an Venedig abzutreten, falls mit der Republik ein Vertrag geschlossen werden sollte.

\section{Mai 1 Basel.}

Sigismundus etc. notum etc. Quemadmodum superiori tempore, dum adbuc romano regio nomine fungeremur, magnifico militi Gaspari Sligk cancellario nostro fideli et sincere dilecto castrum Bassani cum universis et singulis iuribus et pertinenciis suis dedimus et contulimus et donamus, prout litere nostre maiestatis de super date clarius attestantur, nos volentes prefatum eancellarium nostrum, heredes et successores suos in huiusmodi donacione nostra graciosius solidare, eis in verbo cesareo et ex certa nostra sciencia promittimus et pollicemur, quod si unquam nos aut successores nostros Romanorum imperatores seu reges cum illustri dominio Venetorum contingerit aliquam inire concordiam sub quacumque forma illa facta fuerit, quod eidem dominio nequaquam dabimus titulos aliquos de prefato castro et dominio Bassani, nisi cum bona voluntate et contentamento eorum. Quod si secus fecerimus, totum sit irritum et inane preiudicio prefati cancellarii nostri, heredum et successoram suorum. Presencium sub maiestate. Datum Basilee anno domini 1434, die prìma mensis Maii etc.

Reichsregister K. 233.

VI.

K. Sigismund bestätigt seinem Kanzler Kaspar Schlick die adelige Abstammung und die Ebenbürtigkeit seiner Ehe mit Herzogin Agnes von Oels.

\section{Juli 25 Eger.}

Wir Sigmund etc. Bekennen etc. für uns und unser nachkomen. Als wir iczund die hochgeboren furstin Agnesen herczogin in Slesien; zur Olsen und zur Kozel, unsere liebe mume, dem edelen Gaspar Sligk, ritter, burggraven zu Eger und zum Ellebogen, unserm canczler, rat und lieben getreuen zu einem elichen gemalhel gegeben haben, durch solcher redlichkeit willen, die der egenante Gaspar an im hat und ouch das er uns von jugent off merbliche dinst und treue beweist hot und ouch das die wolgeboren Constancia sein muter aus dem edelen stamme der marggraven von T'ervis und Colalt und ouch graven von Camin komen ist, also das er in welschen landen mit fursten, graven und heren dadurch gros gafronet ist, als wir das personlich, als wir in welschen landen waren, gesehen baben und solche heren, seine frund mit sampt im fur uns gewesen sind, dorumb wir in ouch vor elichen jaren zu einem freiherrn und bannirherrn gemacht haben, als die briefe ${ }^{1}$ ) darüber gegeben das auszweisen und wir ouch die egenante Agnesen von jugunt off an unserm hoffe erczogen haben und ir durch irer togund willen allzeit vor andern gnedig gewest sein; und derworten, das sie hinfur solchs heirats nicht entgelde, sunder irer furstlichen geburt

1) Im Register verstümmelt. 
und wirdikeit gebrauch und geniss, wie wol das in keisserlichen rechten clar begriffen und geschreben ist, wo eine furstinn einen ritter nimd und nicht aus dem grad des adels greiffet, das sie dadurch an iren wuiden nicht genedert wirt, sunder der gebrouchen sol an allen enden. Jedoch sindemmole das nicht jedermann also kunt ist und selten geschicht, so haben wir das verneuen wollen und setczen, orden und lautern von romischer, keiserlicher machtvolkomenheit in crafft diesz briffs, das die egenante Agnes unsere liebe mume und furstin irer furstenliche geburt ouch der keiserliche rechten volliclich genisse, als das billich ist und von rechts wegen sein sol. Si sol ouch an allen enden, es sei bei schimff oder ernst, zu hofen ader sust, wie man das genennen mag mit sihen, steen ader geen solich stat haben und gebruuchen, als ein furstin haben sol und ir zugebort, daran sie nimand hindern ader dorinn sprechen sol in dhainweis bei unser und nnser nachkomen und des reichs sweren ungnaden. Mit urkund. Maiestas. Geben zu Eger anno etc. 1437 an sand Jacobs tag.

Reichsregister L. 61 .

VII.

K. Sigismund erhebt die Herrschaft Bassann, die er seinem Kanzler Kaspar Schlick geschrnkt hatte, zu einer Reichsgrafschaft und den Kanzler und seine Erben zu Reichsgrafen.

\section{October 31 Prag.}

In nomine sancte et individue trinitatis feliciter amen. Sigismundus dei gracia Romanorum imperator semper augustus ac Hungarie, Bohнmie, Dalmacie, Croacie rex. Ad perpetuam rei memoriam. Magnifico et spectabili militi Gasparo comiti Bassani etc., cancellario nostro et sacri romani imperii fideli dilecto graciam nostram et omne bonum. Sicut a primevo nascentis mundi exordio conditor omnium mira divinaque sua disposicione firmamenti celigeni monarchiam astrorum numerositate ornavit et radiacionum intermixtarum differencias redivivas mensurans intelligenciarum superiorum officia determinavit, instituens ex celsa providencia cunctum fulgorem siderum ab unici solaris luminis munificencia dependere, quod sua radiacionis simulacra sidereis voltibus imprimens eis splen.loris graciam elargitur, nullum penitus integritatis sue detrimentum paciendo, sic eciam sacratissime ordinacionis sue provisio in ipsa machine mundialis monarchia imperialis sublimitatis maiestatem cunctis mortalium potentatibus et preminenciis prefulgentem precipua officii autoritatisque plenitudine soliique augustalis elacione celeherrima consecravit, a cuins quidem imperialis culminis throno, velut e sole radii prodeuntes omnium mnndalium nobilitatum insignia pullularunt, omnes dignitates summunt originem, ab illoque dependent, ut non sit datum alicuius generositatis insigne, quod a gremio non effluxerit cesaree dignitatis, nec per boc cesaree liberalitatis integritas quomodolibet deficit, sed tanto plus splendrt fulgorosiusque lucet radius principantis monarche, quanto plures eius privilegiato decore fuerint illustrati, illi potissime, qui meritis suis nobiles effectus producunt, sełue civilitatis gloria dignos efficiunt et ipsorum fame preconium actusque celebres redilunt culciores. Sane revolventes in animo gesta veterum, qui nobilitatem summam in virtutibus fundaverunt quodam ferventi desiderio, illos dignos censemus nobilitatis et glorie, qui morum venustate et vir- 
tutum claritate se ipsos exornant. Sic enim victrix Roma, caput orbis, cunctas nundi oras gubernans nobilitatisque ordinem fundans nobis exemplum prebuit, que plus virtutum propriis quam progenitorum meritis nobilitatem recensuit, arlitrans iusta quidem sentencia, plus propriis quam alienis facinoribus gloriari. Sic eciam populus urbis non progenitorum sed virtutum claritate fulgentes senatoria dignitate dignos iudicavit elegitque, qui et consules patresque conscriptos dederunt et gravissimos sanccierunt, nec abfuit quin eciam plebeis eorum poscentibus meritis contribuerunt ius annulare eosque nobilibus pares effecerunt, quibus effectum est, ut Roma celeberrima mundum domaret, provincias regeret, legibusque constringeret cunctosque incitaret ad virtutes et clara facinora, et quanto plus omnes ad consequenda nobilitatis et glorie prtmia aspirabant, tanto amplius excrescebant virtutes, quibus res publica tutabatur et conservabatur. Quid enim Scipiones, quid Fabricios, quid Cathones multosque alios quorum gloria atque merita tanta sunt ut alciorem exaracionem deposciant, eterna fama dignos fecit, quam eorum virtutes et merita, non quidem parentum propago, non generis nobilitas, quibus etsi forsan claruerunt, plus tamen virtus, labor, studium et defensio patrie immortalem ipsorum titulum ampliarunt, ut bellırum et exercitaum exinde ex parvo magni duces effecti sint gradu. Et ne gestis priscorum diviciis inmoremur, ad te, dilecte Gaspar noster, nos convertimus, qui licet progenitorum propagine sis nobilitate conspicuus, alto tamen animo hiis non contentus, te propriis virtutibus nobilitatis nisus es, ut non tantum ex aliis in te derivaretur nobilitas, sed tu tibi ipsi tuisque esses quodammodo nobilitatis origo. Quamvis enim a patre tuo Henrico esses de militari genere procreutus, de quo sufficiens testimonium pridem recepimus et de materna prosapia ex inclitis comitibus de Colalto, cum generosa genetrix tua Constancia fuerit illustris Rollandi marchionis Teruisii, comitis Colalti et sancti Salvatoris legitima filia, nata ex generosa Beatrice comitissa Camini ava tua, habeasifue affinem illusirem principem marchionem Mantue ceterosque magnates Italie, qui omnes dum in Italie partibus ageremus, nos una tecum visitaverunt de huiusmodi parentela nobis informacionem claram alfferentes, ita ut de sufficiencia tue nobilitatis atque propaginis nullus posset penitus dubitare. Instıtuisti tamen forti animo ea omnia leviter ferre et te pocius meritis tuis ac virtute pristine nobilitati preferre, actumque est, ut te nostris serviciis teneris ad huc constitutus in annis vendicares et per viginti et ultra annorum curricula lateri nostro adherens sollicituline tua atque ingenio vires etatemque taliter superasti, ut tandem probitate tua poscente dignus iudicatus es summi cancellariatus officio, quod tam legaliter et laudabiliter peregisti, ut te de digno ad digniora evehere sedulo contenderemus. Et ut relictis gestis tuis, que ampla sunt, saltim ad decus tuum aliqua referamus: provectus es quidem nobiscum ex Constanciensi sacro synodo generali per partes Sabaudie atque Arelati ad Kathalanorum provinciam, ubi in civitate Perpiniani Arrogonie regem, ceterorumque Hispanie regum oratores convenimus, tantumque effecimus, quod abstracta obediencia Petri de Luna, Benedicti XIII nuncupati, in felici nostro reditu ad sacrum concilium semotis tribus capitibus, quibus ecclesia sancta dei erat monstruose longis temporibus deturbata, unum lumen nostra interposicione mundo effulsit. Tandem te misimus crebro in legacionibus nostris 
ad reges prefatos, cum quibus tibi commissa pro nostro honore laudabiliter expedisti. Profiscentibus denique nobis ad Avinionem et tandem per Delphinatum ad regem Francie et tandem Parisiis; ulterius quoque ad regnum Ánglie pro pacifacione eorundem regnorum nunquam lateri nostro defuisti, sed pro modulo tuo nobis semper continua exhibuisti servicia:

Redeuntibus autem nobis ad Constanciam et completa sanctissima unione ecclesie, properantibusque nobis ad peculiare regnum nostrum Hungarie, ubi insultantibus Turcis apparatum bellicum instruxeremus et repressis eis constructoque castro Gorini victores recessimus, te tunc milicie premio verbo regio dignum iudicantes; affuisti tandem nobiscum contra Turcos in secunda expeditione Brassoviensi dum Walachiam eriperemus de manibus eorum et in tercia quidem dum castrum Taubenstein teneremus obsessum. $\mathrm{Tu}$ iam etate, honore, familiaque plus provectus, armorum exercicio et militari disciplina multos alios anteibas, ubi tandem bellum commixtum fuit, cui interfuisti nobis fideliter assistendo, et in quarto quidem apparatu, dum Omaroch princeps Turcorum Novam Burdam innumerabili multitudine tenebat vallatam, nosque in Rascia teneremus exercitum, tu nobis continue prioribus digniora addiciens astitisti. Quid dicemus de plurimis ambasiatis perarduis, quibus maiestati nostre ad regem Polonie, ducem Witoldum et ordinem Prutenorum sepenumero prudencia, industriaque tuis te utilem effecisti. Succedente tamen tempore, dum Boemorum negocium nobis incumberet, in eodem regno nobis immensa impendisti servicia et in bello qnidem Wissegradensi et Brodensi cum non mediocra lesione tue persone laude digna opera exercebas, in omnibusque guerris, exercitibus tractatibusque et ambasiatis in ipso regno decem et octo fere annis durantibus, qui amplissima egerent dissercione, te talem reperimus, ut te nobis proficuum et dignum bonore, extollendumque censeremus et baronie titulo insigniremus. Quantum autem in Alamanie partibus apud principes et communitates tui usi simus tempore nostri regiminis propter officium, quod gerebas et geris, cum sit vulgare atque notissimum, stilum retrahendum censuimus. Et ea que in Italia acquisivisti dicturi sumus. Dum enim deliberaremus pro suscipiendis imperialibus infulis et recuperandis imperii iuribus Italie partes transcendere, tu cum magnatibus et communitatibus Italie convenientem nobis additum preparasti: et sic Mediolanum intravimus et suscepta regali corona more predecessorum nostrorum ulterius ad urbem ad complementum imperialium ceremoniarum aspiravimus, penetrantesque Lombardiam et obstantibus nobis sanctissimo domino nostro papa, qui concilium generale Basiliense, nostra protectione pro christianismi salute institutum et cui adherebamus, conabatur dissolvere, obstantibusque Florentinis et colligatis eorum, ut tunc erant Veneti, non poteramus commode Etrurie fines attingere, quamvis sanctitas domini nostri ut desereremus concilium nobis polliceretur coronas et iter securum, omnesque honores possibiles, que omnia tamquam insipida postergavimus, arbitrantes dignius res nostras forti et regio animo cum honestate quamvis dampno et non mediocri periculo velle prosequi, quam signa honoris tamquam victi cum dedecore reportare. Sicque petivimus Tusciam et civitatem Lucanam, tandem per acies hostiurn ad fidelem imperii civitatem Senensem devenimus cotidiana solum nostra familia circumcincti, ubi fere per annum inter hostes versantes, nam et dux Mediolani nobis depost denegebat presidium, 
cotidianis fluctuavimus adversitatibus et erumpnis, nec nobis aliquis erat amicus ant locus refugii. Sed tu fidelis Gaspar, comes ingenue, sicuti precedenti etate, opera et studio tuis multa fuerunt commoda nobis parta; ita de fideli te fideliorem exhibendo iterum et iterum replicatis vicibus Romam adiisti, adhortatus es summum pontificem et ipsum, qui prius pluribus celeberrimis ambasiatis mitigari non poterat, industria tua opitulanteque affeccione, quam tibi sanctitas sua gerebat, ad nostra beneplacita convertisti et factis capitulis prestitoque iuramento solempni, quod tu cum magnifico Matkone comite peragebas, nostris laboribus et curis finem dedisti, ita ut Romam iremus et suscepti maxima gloria et triumpho, per manus sue sanctitatis fuimus solemniter infulati. Tantaque erat animorum nostrorum coniunctio, tanta benignitas patris ad filium, filique affectio versus patrem, ut omnia feliciter ad vota succederent, ubi te eciam in ponte Tiberis more veterum equo insidentem pre multis magnatibus eligendo inter milites primum cinximus et militari honore tamquam benemeritum dignum indjcavimus. Et quia reditus noster propter ceteros hostes nostros erat suspiciosus periculo, tu ut nobis omnia complanares apud summum antistitem operam addidisti ut et cum Venetis, hostibus tunc nostris, certorum annorum treuga indiceretur, qua factum est, ut ubi pridem insultati, oditi et cum aliquali defectu quandoque intrabamus, cum honore et cum gloria ac habundancia rerum partes illas exivimus. Et venientes Basileam unionem ecclesie Dei conservavimus, ubi et tu nobis perutilis astitisti. Sunt multa alia depost per te acta, que forent hic dignissime recensenda, sed sufficiant hec pro laude tua, que eciam apud priscos quemcunque virorum immortali gloria dignum consecrassent. Que omnia si rite perpenderimus, spectabilis comes Gaspar, quid est, quod non merearis, quid tibi conferre poterimus aut nobilitatis, aut glorie, aut dignitatis, quod huiusmodi merita tua non superent! Profecto tibi tenetur ecclesia, tenetur imperium, tenentur regna nostra, nosque tibi, tuisque posteris sumus ad omnia tua commoda et honores obligatissimi debitores! Et ut pro huiusmodi tuis debitis tibi saltem aliquid impendamus, quatenus alii exemplo tuo incitati ad virtutes nanciscendas efficiantur promptiores, te Gasparum prefatum, quem prius baronie titulo insignivimus iuxta continenciam aliarum nostrarum litterarum, cui tandem eciam tamquam benemerito illustrem principem Agnetem ducissam Slesie, Olsnicie et Kozolie etc., consanguineam nostram carissimam, contoralem tuam matrimonialiter copulavimus ut tua merita, coniugisque tue alta prosapia posteritati vestre relinquant eternum nobilitatis honorisque nomen, volentes tibi, qui ut prefertur utrorumque parentum et propriis eciam choruscas meritis, existisque ingenuus, amplioris dignitatis addere cumulum, qui in Romana republica plus priscis evis pro tam claris facinoribus meruisses, te Gasparem memoratum, heredes fratresque tuos ${ }^{1}$ ) et omnes qui ab eis descenderint maturo principum, comitum, baronum et procerum nostrorum accedente consilio et de certa sciencia uberius in dei nomine libertamus $\operatorname{vosque^{2}}$ ) omni meliori modo et forma, quibus fieri potest, comites çastri, civitatis et territorii Bassani, cuius te pridem privilegio nostro dominum fecimus, creamus, facimus, constituimus, extollimus

1) Auf Rasur von derselben Hand. Im Register steht heredesque tuos legitimos, qui de lumbis tuis descenderint.

3) Auf Rasur von derselben Hand. Im Register steht: seque. 
et auctoritate cesarea, tenore presencium gratiose sublimamus, dominiumque Bassani in comitatum nobilem sacri imperii erigimus, et ut quevis comitum dominia et comitatus donacionis, derolucionis seu empcionis titulo possidere possitis, vos habiles facimus, volentes et decernentes, ut tu, fratresque $e^{1}$ ) tui legitimi, ut prefertur omni honore, iure, titulo, dignitate, prerogativa, libertate et preeminencia in perpetuum gaudere et frui possitis et debeatis apprehensa possessione prefati comitatus sive non, quibus ceteri sacri imperii comites ingenui gaudent et utuntur in iudiciis sive extra, in ioco, serio, bellis, duellis, torneamentis, hastiludiis, banderiis cum sigillacione cere rubee, sive alibi ubicunque de consuetudine vel de iure. Nulli eciam penitus hominum ad provocacionem duelli seu alterius cuiuscunque cause criminalis sive civilis cuiuscunque eciam condicionis existat stare aut respondere tu, tuique fratres${ }^{2}$ ) legitimi debeatis, nisi comitatus insigniis fulcito et in tanto nobilitatus gradu constituto, neque sentencias interlocutorias seu diffnitivas, seu testimonia pro antedictis causis subire, pati aut racione quacunque, nisi fuerit comicia ingenuus, ut prefertur. Volumus eciam et auctoritate imperiali decernimus ut tu fratresqu $\mathrm{e}^{3}$ ) tui all nullum penitus iudicium, sive sit iurlicium curie nostre, seu alterius cuiuscunque sive etiam provinciale aut terrestre, generale aut speciale provocati, trahi, citari seu in eodem iudicari seu sentenciari debeatis pro quacunque causa, nisi coram persona nostre maiestatis seu successorum nostrorum Romanorum regum seu imperatorum seu commissariis ipsorum, qui in curiis eorundem fuerint ad hoc specialiter deputati, quidque autem secus feret in citando, iudicando aut sentenciando, totum penitus annnullamus et cassamus decernentes auctoritate prefata hoc nullius fore roboris vel momenti nec prefatis Gaspari et fratribus ${ }^{4}$ ) suis hoc posse aut debere preiudicare, demptis negociis feudorum, que semper coram dominis feudi iudicaliter debent diffiniri, quibus per hanc nostram libertacionem non intendimus derogare, non obstantibus in premissis omnibus, quibuscunque legihus, statutis, consuetudinibus, iuribus seu privilegiis in contrarium editis seu edendis, quibus omnibus in quantum huic nostre concessioni et creacioni obviare viderentur, auctoritate cesarea et de plenitudine potestatis derogamus et derogatum esse volumus per presentes. Gauileas igitur favore cesareo dilecte comes Gaspar et de tanto sublimacionis munere eciam tua proles exultet et tanto uberius ad sacri imperii commoda insudare curetis, quanto vos amplius preventos conspicitis beneficiis graciarum. Nulli ergo omnino hominum liceat banc nostre creacionis, gracie et sublimacionis paginam infringere aut ei quovis ausu temerario contraire. Si quis autem hoc attemptare presumpserit nostram et imperii sacri indignacionem gravissimam et penam centum marcarum auri purissimi, quam unusquisque, qui contrafaceret, tociens, quociens se noverit, irremissibiliter incursurus, medietatem impeliali erario, reliquam vero partem prefato comiti Gaspari et eius fratribus $s^{5}$ ) persolvendas, ad cuius quidem pene importacionem eis plenariam concedimus facultatem contrafacientes et mandatorum nostrorum

1) Anf Rasur von derselben Hand. Im Register: heredesque.

2) Auf Rasur von derselben Hand. Im Register: suique heredes.

8) Auf Rasur von derselben Hand. Im Ringister: heredesque tui.

4) Auf Rasur von derselben Hand. Im Register steht: heredibus.

s) Auf Rasur von derselben Hand. Im Register steht: heredibus. 
transgressores eciam sine iudicio arrestandi et detinendi, quousque camere et ipsis pro huiusmodi pena fuerit plenarie satisfactum, nec ipsi per hoc aliquam incurrere debent notam sive culpam. Presencium sub nostre imperialis maiestatis sigillo testimonio litterarum, datum Prage, anno domini 1437 penultima die Octobris, regnorum nostrorum anno Hungarie etc. 51, Romanorum 28, Bohemie 18, imperii vero 5 .

Ad mandatum domini imperatoris in suo consilio $\mathrm{H}$.

Orig. auf Perg., Kopidlno 1V. 5. Reichsregister L. 59|v Majestätssiegel an schwarzgelben Schnüren, Heffner Tuf. XIII. 96 und 97. A tergo: Registrata. Alte Sign. $d X I$. und $f V I, 15$. oder 16. Jhd. Regest und Datum 17. und 18. Jhd.

\section{VIII.}

\section{K. Albrecht schenkt Kaspar Schlick das Schloss Uivár in Ungarn. 1438 April 30 Pest.}

Nos Albertus, dei gracia rex Hungarie, Dalmacie, Croacie etc. Austrieque et Stirie dux, nec non marchio Moravie ete. Presentis et postere etatis hominum noticie patefacimus presencium per tenorem: quamquam quorumvis nativa liberalitas donis munificencie benemeritis subditis erogandis habundans cunctorum suorum fidelium subiectorum merita eorundem nibilominus pensata qualitate, quam experta quantitate, retribucione votiva prosequi teneatur; attamen illis longe forcius et specialius sue gratitudinis debet offere benivolenciam, quos nedum preteritorum servi iorum fructuosa exhibicio, verum eciam futurorum impendendi aptitudo revera commendabiles representat, quique ad huiusmodi grata obsequia sicuti viribus et exercicio, sie nihilominus consilio impendenda, utiles atque apti claris precendencium indiciis aperte indicantur. Sane inter ceteros sed et ut clarius dicamus pre ceteris suis participibus, uti fidedigno edocti sumus testimonio, fidelis noster gratus et sincere dilectus magnificus Gaspar Sligk miles, alias quondam excellentissimi recolende memorie principis donini Sigismundi Romanorum imperatoris semper augusti et Hungarie, Bohemie etc. regis, patris nostri carissimi imperialis et regni Bohemie cancellarius, erga eundem patrem nostrum a sue adolescencie primeve temporibus tali fulsit fide et devocione ac famulandi promptitudine, totque et tanta existunt sue laudande fidelitatis obsequia, serviciorumque non indigne memoranda merita, quibus idem Gaspar cancellarius ipsi quondam domino imperatori patri nostro se gratum reddere studuit, quod si ipsius geste et habite rei seriem stili officio pro presenti vellemus describere, vix apparet modus de presenti, quo id ipsum, cum nec expressione valeat conprehendi, per singula posset efficaciter explicari. Sed ne prorsus eius devocionis constancia et famulandi promptitudo silencii vicem recipiat, aliqua eiusdem laudabilia servicia ingi memoria merito recolenda ceteris veluti exemplar et speculum pro obiecto reponenda presentibus conpendiose censuimus annotanda.

Dudum siquidem decursis et evolutis prefuti Gaspar Sligk etatis adolescencie temporibus, in quibus et paulo ante forsitan serviciis annotati quondam domini imperatoris et sue cancellarie imperialis fideliter inherens sibi servicia tam etati, quam providencie et sciencie suis eotunc congruencia studiose exhibuit, eodemque Gaspar ad alcioris noticie ipsins domini im- 
peratoris gradum suis virtutibus exposcentibus provecto in pluribus immo multiplicibus exercitualibus expedicionibus, tam contra insultum sevissimorum Turcorum crucis Christi persecutorum, quam eciam adversus rabiem perfidorum Hussitarum et Taboritarum per ipsum quondam dominum imperutorem, prout imminentis necessitatis qualitas exigebat, post sese instauratis, dictus Gaspar Sligk inchoate fidelitatis et famulandi gratitudinem propensius exercitare cupiens decenti suorum familiarium comitiva fulcitus, non sine suis laboribus, magnisque sumptibus et expensis ipsi domino inperatori et sue sacre corone iuxta tocius sue possibilitatis exigenciam acceptabilia servicia curavit studiosus et multis vicibus exhibere. Quilus quidem suis obsequiis requirente ipso, tandem magis ac magis dileccionem sue persone erga dictum quondam dominum imperatorem attingente, suisque consiliis interesse promerente, primum in tractatibus inter ipsum dominum imperatorem et Bohemos, tunc pro bono pacis opportune habitis et demum in ambasiata et legacione non parve, immo grandis importancie ad Polonos et Prutenos sibi veluti viro prudencia et providencia predito per dictum quondam dominum imperatorem deferri imposita, per eum quoque tam sagaciter quam provide et votive expedita et pacta, nodo simili pergrata famulamina ipsi domino imperatori exhibuit et impendit. Postmodum vero hiis omnibus prout opus erat expeditis, certisque subsequentibus interpositis diebus annotato quondam domino imperatore pro babendis et finaliter suscipiendis ultimis duabus coronis seu infulis imperialibus partes Alamanie et deinde Lombardie adeunte, susceptaqua in Mediolano una coronarum pretactarum, ulterius ad Tusciam et alias Italie regiones usque civitatem Senarum inclusive per multas insidias et obstacula, quas eotunc inter ceteros imperii rebelles a Florentinis protulisse dinoscitur, successive procedente, ibidemque aliquamdiu moram protrahente, memoratus Gaspar, qui iam per dictum quondam dominum imperatorem commendabilibus suis virtutibus, morum gravitate, eloquencie facundia et consilii maturitate suadentibus ad honorem cancellariatus susceptus atque promotus eiusdem officio fungebatur per totum ipsius itineris spacium, ubique et sine intermissione lateri ipsius domini imperatoris adherendo, nedum in ipsius cancellarje negociorumque in eadem occurencium fideli expedicione, quin immo eciam in aliis tam scilicet actibus militaribus, quam eciam multarum dissensionum emergencium sedacione, variarum quoque ot multipliciam legacionum nunc ad dictos Florentinos et Venetos, nunc vero ad sanctissinum dominum nostrum Engenium papam quartum sue direccioni traditarum votiva et honorifica expedicione taliter se gessit, tam pergrataque servicia ipsi domino imperatori exhibuit, quod seclusa expressionis prolixitate, ut multa brevi conprehendamus sermone, potissime per ipsius Gaspar cancellarii direccionem, circumspectamque operacionem atque per eius medium ipse dominus imperator sopitis multis differenciis inter eundem ac antelatum dominum papam hincinde subortis in adepcione postreme sue corone imperialis, vota sua existit consecutus, sicque tandem suscepta et habita interveniente procuracione sepefati Gaspar cancellarii per dictum quondam dominum imperatorem de assecucione infularum suarum imperialium plena certitudine, ipsoque de prefata civitate Senarum in almam urbem Romanam se conferente, ibidemque susceptis gloriose de manibus antefati domini pape ipsis infulis imperialibus, viceversa ab illinc ad sacrosanctam Basi- 
liensem concilium regrediente, ipse Gaspar cancellarius, qui pro tunc in cuiusvis generis obsequiorum exhibicione sibi parem non habebat, perclare sue fidelitatis sollerciam in eo a primordio sue etatis iuvenilis radicatam, constanter profectus, ipsum dominum imperatorem non sine maximis expensarum sumptibus, cum non parva immo copiosa sua familia investigans, eidem in rebus et negociis statum reipublice Christiane concernentibus, conciliis in eodem tractatis notabiles et henori eiusdem domini imperatoris non parum convenientes cooperaciones fecit et impendit. Demum vero dum ipse quondam imperator expeditis suis negociis in ipso concilio inchoatis, ad hoc regnum suum Hungarie feliciter rediens in eodem aliquamdiu repausasset, antedictus Gaspar cancellarius ardentis in eo fidei, qua eidem domino imperatori summe afficiebatur zelo, premonitus, non multorum dierum cum eodem inibi morula protracta, cupiens priora recolenda obsequia novorum impensione decorare, ad requisicionem annotati quondam domini imperatoris persone rebusque et bonis suis minime parcens ad pociores regni Bohemie barones, plerumque eciam ad communitatem tocius regni Bohemie in legacione ipsius domini imperatoris se conferens, talem cum eisdem modum et practicam novis adhibitis laboribus tenuit atque fecit, quod tandem eius cooperacione mediante idem dominus imperator certis cum ipsis Bohemis prehabitis convencionibus ipsum regnum suum Bobemie et eius dominium, cuius scilicet regnicole per plurium annorum preteritorum excursum ab obediencia sua, quorundam sceleratorum hereticorum doctrina immissis undique deviis rumoribus aversi, se prorsus alienos fecerunt, plenarie existit assecutus, in quo non solum ipse dominus imperator altissimum honorem et profectum, verum eciam Christiani nominis religio incrementa amplissima susceperunt. Quibusquidem omnibus et singulis pretactis habitis et expletis sepefatus Gaspar cancellarius eciam in aliis pluribus et multiplicibus agendis sue provide expedicioni execucionique et direccioni sepe sepius creditis sine alicuius temporis intervallo, semper decenti familia fulcitus, tam studiose quam sollerter sollicitudine pervigili, strenua operacione et agilitate operosa dicto domino imperatori usque felicem sue vite temporalis occasum acceptabilia, pergrataque et re vera laudum preconio attollenda servicia, quorum nec qualitatis sed nec quantitatis numerus valet faciliter conprehendi, curavit summo opere exhibere, prout super hiis singulis prenotatis sicuti aliorum fidedigno accedente testimonio, sic nibilominus propria nostra contemplacione sepe numero curiam dicti domini imperatoris visitando experienciam sumpsimus evidentem. Que omnia suprafacta pervide et precise, ac si proprie nostre persone exhibita fuissent, pensamus et pensanda arbitramur, cum et in mortis sue articulo prefata maiestas ipsum Gaspar nobis et baronibus regni Hungarie bene tractandum et propter servicia sua nunquam deserendum tenerrime et cordialiter comendavit. Ceterum ne plurimorum virtuosorum actuum antelati Gaspar cancellarii longa et importuna narracio spaciosa prolixitate interveniente animos legencium distrahat, illa in parte sillencio transeuntes aliqua, que et nostra serenitas gratanter suscepit ab eodem, propter maius sue fame preconium premissis duximus addicienda. Porro defuncto iuxta nutum divine disposicionis antelato quondam domino imperatore patre nostro, nobisque summi opificis opitulante clemencia, eidem in regimen huius regni Hungarie feliciter et votiva cum prosperitate succedentibus, memoratus 
Gaspar cancellarius laudabilem suam famulandi sollerciam constanter usque ad bec tempora nostri felicis regiminis accurate transferens, nuper post obitum scilicet annotati quondam domini imperatoris de nostre maiestatis mandato speciali et ob nostram singularem conplacenciam honoris quoque uberrimum incrementum ad (ivitatem Pragensem, ubi scilicet communıtas tocius regni Bohemie eleccionem novi regis habitura fuerat eo tunc congregata, accedens, inibique diligenti operacione interposita in tantum sue discrecionis sagacitate practicavit, quod ex eius induccione, persuasioneque et procuracione plurimorum mentibus in ipsa eleccione discordantibus ad unionem optatam deductis, tandem eleccio huius modi in regimen regni Bohemie prenotati de nostra persona feliciter habita existit et conclusa. Sicque ipse Gaspar cancellarius obtenta eleccione pretacta ad maiestatem nostrum votiva ferens responsa, remeavit deincepsque usque in presenciarum tempus cum nostra permanenilo maiestate in singulis, que nobis veluti regiminis novitate fungentibus placibilia, regnoque nostro Hungarie utilia fuere, taliter se gratum reddere studuit et acceptum, sicuti et in antea certa ex preteritis sumpta fiducia de futuris eum facturum non duhitamus, quod nedum regali remuneracione quantumlibet magnifice impendenda evidenti omnium iudicio dignum se effecit, verum eciam mutuate dileccionis nostre benivolencian ad se attrahere promeruit manifeste. Quibus omnibus singillatim diligenter intuitis, considerati que et perspicaci meditacione pensatis, quamvis altissimis regalibus donariis dictus Gaspar cancellarius merito esset premiandus, tanen tum paternis respectibus, tum etenim in nostri (sic) memorium revocato extremo antelati patris nostri testamento, ubi scilicet idem in suis extremis decumbens, ut premittitur, inter cetera sua acta annotato Gaspar cancellario nobis ibidem coram eo astantibus in fidelissimum servitorem immo pocius filium commendato nos cordintima devocione subiuncto mandato admonuit, at eolem in nostri favorem suscepto sue promocioni totis viribus intendere serviciorumque suorum superius in aliqua parte tactorum sue maiestati impensorum opportunus remunerator existere deberemus, cupientes et volentes ipsum munificencie nostre dono aliquantisper consolari, quotenus et testamento prevocato satisfaccio debita et serviciorum suorum aliqualis remuneracio subsequatur, idemque ad ulteriora nobis et sacre huius regni corone exhibenda obsequia fervencior efficiatur, castrum nostrum Uywaur nuncupatum in comitatu Nitraensi halitum, quod alias quondam magnifici Stiborii di Stiloricz alias de Bolondoch hominis absque heredum sexus masculini solacio defuncti prefuisse et per defectum seminis eiusdem iuxta approhatam regni nostri pretacti legem et consuetudinem ad manus nostras regias devolutum fore dinoscitur, simul cum omnibus et singulis oppidis, villis et possessionibus ac prediis nec non locis sessionalibus, terris arabilibus, cultis et incultis, agris, pratis, forestis, silvis, nemoribus, rubetis, montibus, vallibus, vineis et vinearum promontoriis, aquis, fluviis, piscinis, piscaturis, molendinis et locis molendinorum, sed et ecclesiarum patronatibus, item tributis ac lacro camere nostre regie in et de oppidis, villis et possessionibus pretactis provenire solitis, ceterisque universis proventibus, fructibus, iuribus, jurisdictionibus, obvencionilusque et emolimentis et generaliter quarumlibet utilitatum et pertmenciarum integritatibus quocumque nomine rocitatis ad dictum castrum de iure et ab antiquo spectantibus, sub suis et eorundem oppidorum ac dictarum villarum, possessionum et 
prediorum veris metis et antiquis limitibus, sub quibus scilicet per antelatum quondam Stiborium tente fuerunt et possesse, ex certa nostra sciencia et animo deliberato, de consensu eciam et beneplacita voluntate serenissime domine Elizabeth regine, filie scilicet antelati quondam domini imperatoris, conthoralis nostre carissime, prelatorumque et banorum nostrorum ad id accedente consilio prematuro, prefato Gaspar Sligk cancellario perinde et tamquam vero regnicole per universitatem dictorum prelatorum et baronum ac nobilium antefati regni nostri Hungarie in eorum consorcium et medium suis meritis exigentibus sollempniter recepto et assumpto, suisque heredibus et posteritatibus universis de manibus nostris regiis omni eo iure, quo nostre incumbunt collacioni, dedinus, donamus et contulimus, immo damus, donamus et conferimus iure perpetuo et irrevocabiliter possilendum, tenendum, pariter et habendum salvo iure alieno et nibilominus ex habundanciori nostre gracie benevolencia assumimus nostro et successorum nostrorum regum scilicet Hungarie nominibus antelatum Gaspar cancellarium suosque heredes universos in pacifico dominio dicti castri et suarum pertinenciarum pretactarum et contra quosvis impetitores causidicos et actores, nostris et eorumdem successorum nostrorum laboribus propris et expensis iuxta et extra iudicium semper et ubique conservare, protegereque et expedire, harum nostrarum vigore et testimonio litterarum mediante. Quas in formam nostri privilegii redegi faciemus, dum nobis in specie fuerunt reportate. Datum Bude, feria secunda proxima post dominicam Iudica, anno domini 1438 .

$$
\text { Commissio propria domini regis }{ }^{1} \text { ). }
$$

Orig. auf Perg., in Kopidlno X. 3. Das Siegel war aufgedrückt unter dem Texte in der Mitte am Rande. A tergo: Registrata.

1) Zweimal geschrieben in der Urk., einmal ober dem Texte oben am Rande rechts, dann unter dem Texte am Rande unter dem aufgedrückten, jetat. abgefallenem Siegel. Unten in der rechten Ecke: Lecta. 